\title{
A draft genome and transcriptome of common milkweed (Asclepias syriaca) as resources for evolutionary, ecological, and molecular studies in milkweeds and Apocynaceae
}

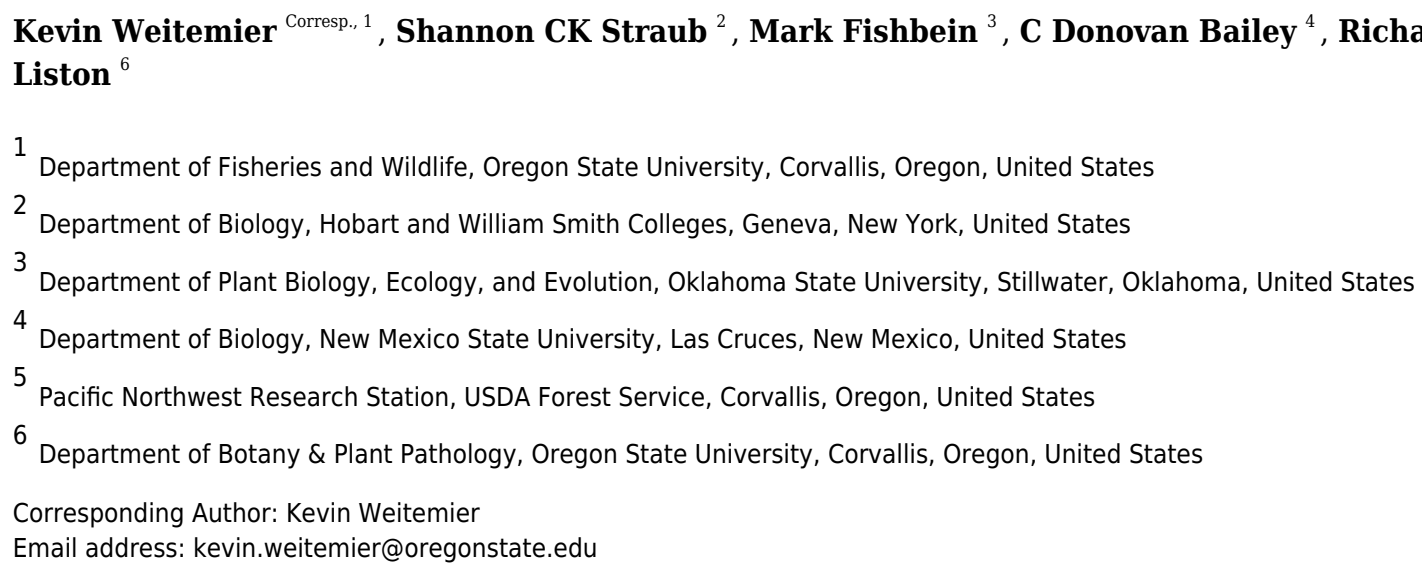

Milkweeds (Asclepias) are used in wide-ranging studies including floral development, pollination biology, plant-insect interactions and co-evolution, secondary metabolite chemistry, and rapid diversification. We present a transcriptome and draft nuclear genome assembly of the common milkweed, Asclepias syriaca. This reconstruction of the nuclear genome is augmented by linkage group information, adding to existing chloroplast and mitochondrial genomic resources for this member of the Apocynaceae subfamily Asclepiadoideae. The genome was sequenced to $80.4 \times$ depth and the draft assembly contains 54,266 scaffolds $\geq 1 \mathrm{kbp}$, with N50 $=3415 \mathrm{bp}$, representing $37 \%$ (156.6 Mbp) of the estimated $420 \mathrm{Mbp}$ genome. A total of 14,474 protein-coding genes were identified based on transcript evidence, closely related proteins, and ab initio models, and $95 \%$ of genes were annotated. A large proportion of gene space is represented in the assembly, with $96.7 \%$ of Asclepias transcripts, $88.4 \%$ of transcripts from the related genus Calotropis, and $90.6 \%$ of proteins from Coffea mapping to the assembly. Scaffolds covering $75 \mathrm{Mbp}$ of the Asclepias assembly formed eleven linkage groups. Comparisons of these groups with pseudochromosomes in Coffea found that six chromosomes show consistent stability in gene content, while one may have a long history of fragmentation and rearrangement. The progesterone $5 \beta$-reductase gene family, a key component of cardenolide production, is likely reduced in Asclepias relative to other Apocynaceae. The genome and transcriptome of common milkweed provide a rich resource for future studies of the ecology and evolution of a charismatic plant family. 
1 A draft genome and transcriptome of common milkweed (Asclepias syriaca) as resources for

2 evolutionary, ecological, and molecular studies in milkweeds and Apocynaceae

3

4 Kevin A. Weitemier ${ }^{1,7}$

5 Shannon C. K. Straub ${ }^{2}$

6 Mark Fishbein ${ }^{3}$

7 C. Donovan Bailey ${ }^{4}$

8 Richard C. Cronn ${ }^{5}$

9 Aaron Liston $^{6}$

10

$11{ }^{1}$ Department of Fisheries and Wildlife, Oregon State University, 104 Nash Hall, Corvallis, OR 12 97331, USA

13 22Department of Biology, Hobart \& William Smith Colleges, 113 Eaton Hall, Geneva, NY 14456,

14 USA

$15{ }^{3}$ Department of Plant Biology, Ecology \& Evolution, Oklahoma State University, 301 Physical

16 Sciences, Stillwater, OK, 74078, USA

$17{ }^{4}$ Department of Biology, New Mexico State University, PO Box 30001, MSC 3AF, Las Cruces,

18 NM, 88003, USA

$19{ }^{5}$ Pacific Northwest Research Station, USDA Forest Service, 3200 SW Jefferson Way, Corvallis,

20 OR, 97331, USA

$21{ }^{6}$ Department of Botany \& Plant Pathology, Oregon State University, 2082 Cordley Hall,

22 Corvallis, OR 97331, USA

$24{ }^{7}$ Corresponding author:

25 Kevin Weitemier 
26 Department of Fisheries and Wildlife, Oregon State University, 104 Nash Hall, Corvallis, OR

27 97331, USA

28 Fax: 541-737-3590

29 kevin.weitemier@oregonstate.edu

30

31 Keywords: Genome, Asclepias, milkweed, Apocynaceae, cardenolide, chromosome evolution 32

33 Running Title: Asclepias nuclear genomic resources 


\section{ABSTRACT}

35 Milkweeds (Asclepias) are used in wide-ranging studies including floral development,

36 pollination biology, plant-insect interactions and co-evolution, secondary metabolite chemistry,

37 and rapid diversification. We present a transcriptome and draft nuclear genome assembly of the

38 common milkweed, Asclepias syriaca. This reconstruction of the nuclear genome is augmented

39 by linkage group information, adding to existing chloroplast and mitochondrial genomic

40 resources for this member of the Apocynaceae subfamily Asclepiadoideae. The genome was

41 sequenced to $80.4 \times$ depth and the draft assembly contains 54,266 scaffolds $\geq 1 \mathrm{kbp}$, with N50=

$423415 \mathrm{bp}$, representing 37\% (156.6 Mbp) of the estimated $420 \mathrm{Mbp}$ genome. A total of 14,474

43 protein-coding genes were identified based on transcript evidence, closely related proteins, and

44 ab initio models, and 95\% of genes were annotated. A large proportion of gene space is

45 represented in the assembly, with $96.7 \%$ of Asclepias transcripts, $88.4 \%$ of transcripts from the

46 related genus Calotropis, and $90.6 \%$ of proteins from Coffea mapping to the assembly. Scaffolds

47 covering $75 \mathrm{Mbp}$ of the Asclepias assembly formed eleven linkage groups. Comparisons of these

48 groups with pseudochromosomes in Coffea found that six chromosomes show consistent stability

49 in gene content, while one may have a long history of fragmentation and rearrangement. The

50 progesterone $5 \beta$-reductase gene family, a key component of cardenolide production, is likely

51 reduced in Asclepias relative to other Apocynaceae. The genome and transcriptome of common

52 milkweed provide a rich resource for future studies of the ecology and evolution of a charismatic

53 plant family. 


\section{INTRODUCTION}

55 The development of genomic resources for an ever-increasing portion of the diversity of

56 life is benefiting every field of biology in myriad ways. The decreasing cost of sequencing and

57 the continual development of bioinformatic tools are allowing even single labs and small collaborations to produce genomic content that is beneficial and accessible to the wider research community. This study presents such a resource, including a draft genome assembly of a species in the milkweed genus Asclepias (Apocynaceae).

Asclepias sensu stricto is made up of about 130 species in North and South America

62 (Fishbein et al., 2011). The genus in the Americas is found in a wide range of habitats, from deserts to swamps, plains to shaded forests, and may represent a rapid ecological expansion

64 (Fishbein et al., 2018). The common milkweed, Asclepias syriaca L. (Fig. 1), inhabits wide swaths of eastern North America, westward to Kansas, and northward to Canada (Woodson, 1954). It is well known for the milky latex exuded when injured, showy inflorescences, and pods filled with seeds tufted with fine hairs.

As members of Apocynaceae subfamily Asclepiadoideae, Asclepias species possess floral

69 architectures unique among plants, including floral coronas and a central gynostegium composed

70 of the unified stamens and pistil (Fig. 1). Most Asclepias species are nearly or entirely self-

71 incompatible (Wyatt \& Broyles, 1994), and their pollen is packaged into masses, pollinia, which

72 are transferred as a unit from one flower to another. This usually allows a single successful

73 pollination event to fertilize all of the ovules in an ovary, resulting in full-sibling families in each

74 fruit (Sparrow \& Pearson, 1948; Wyatt \& Broyles, 1990). The unusual features of Asclepias

75 pollination and floral architecture have positioned it as a model in studies of angiosperm

76 reproductive biology (Broyles \& Wyatt, 1990; Wyatt \& Broyles, 1990, 1994), floral development

77 (Endress, 2006, 2015), selection on floral characters and prezygotic reproductive isolation 
78 (Morgan \& Schoen, 1997; La Rosa \& Conner, 2017), and floral display evolution (Willson \&

79 Rathcke, 1974; Chaplin \& Walker, 1982; Fishbein \& Venable, 1996).

$80 \quad$ Milkweeds produce an array of potent secondary compounds, including cardiac

81 glycosides (specifically cardenolides). Some herbivores possess defenses to avoid or tolerate

82 these compounds, including the monarch butterfly, Danaus plexippus. Monarch caterpillars are

83 able to sequester cardenolides from Asclepias to use for their own defense, and Asclepias are an

84 essential host for monarchs (Brower, Brower \& Corvino, 1967). The variation within and among

85 Asclepias species in types of and investments in defensive compounds and structures has led to

86 studies of defensive trait evolution (Agrawal \& Fishbein, 2006, 2008; Rasmann et al., 2009,

87 2011; Agrawal et al., 2012; Fishbein et al., 2018; Livshultz et al., 2018), plant-herbivore

88 ecological interactions (Brower, Brower \& Corvino, 1967; Brower et al., 1972; Vaughan, 1979;

89 Van Zandt \& Agrawal, 2004), and plant-herbivore co-evolution (Agrawal \& Van Zandt, 2003;

90 Labeyrie \& Dobler, 2004; Agrawal, 2005).

91 A few genomic resources have been developed for Asclepias and other Apocynaceae. The

92 chloroplast and mitochondrial genomes of $A$. syriaca have been sequenced (Straub et al., 2011,

93 2013), and flow cytometry estimates place the nuclear genome size of A. syriaca at $420 \mathrm{Mbp}$

94 (Bainard et al., 2012; Bai et al., 2012). Asclepias is not the first member of Apocynaceae to

95 receive nuclear genome sequencing. Genomic sequencing and assembly of Catharanthus roseus

96 (Rauvolfioideae) was performed by Kellner et al. (2015) to investigate the production of

97 medicinal compounds (Table 1). Sabir et al. (2016) assembled the genome of Rhazya stricta

98 (subfamily Rauvolfioideae) and Hoopes et al. (2017) assembled the Calotropis gigantea

99 (Asclepiadoideae) genome, investigating alkaloid diversity and cardenolide production,

100 respectively (Table 1$)$.

101 The transcriptomes of several species of Apocynaceae have also been released as part of 102 broader investigations into medicinally important plants, particularly those producing 
103 monoterpene indole alkaloids, including Tabernaemontana elegans (Rauvolfioideae), Rauvolfia

104 serpentina (Rauvolfioideae), Rhazya stricta, and Catharanthus roseus (Medicinal Plant

105 Consortium, 2011; Góngora-Castillo et al., 2012a; Xiao et al., 2013; Yates et al., 2014; Park et al.,

106 2014). The transcriptome of Calotropis procera has also been investigated (Kwon et al., 2015;

107 Pandey et al., 2016; Hoopes et al., 2017).

108 Outside of Apocynaceae the most closely related species to milkweed with a sequenced

109 genome is the diploid ancestor of coffee, Coffea canephora (Rubiaceae; Denoeud et al., 2014).

110 Coffea is in the same order as Asclepias, Gentianales, and C. canephora has the same number of

111 chromosomes: $x=n=11,2 n=22$ (Denoeud et al., 2014). The Coffea genome assembly is a high-

112 quality reference, with large scaffolds ordered onto pseudochromosomes (scaffolds that have

113 been ordered based on linkage information, as though on a chromosome; Table 1).

114 The genomic assembly of Asclepias syriaca presented here includes a nearly complete

115 representation of gene space, supported by transcriptome evidence. The heterozygosity present in

116 this obligate outcrossing species is used to develop a panel of SNPs that can be captured via

117 targeted enrichment, and a set of offspring from the sequenced individual is used to cluster

118 assembled scaffolds into linkage groups. A comparison of linkage groups between Asclepias and

119 Coffea is presented, providing insights into chromosome organization in Asclepias, and

120 chromosomal evolution within Gentianales. Both genome and transcriptome sequences are used

121 to explore gene family evolution, especially as related to cardenolide biosynthesis.

\section{METHODS}

\section{Tissue preparation and library construction}

124 Leaf tissue of Asclepias syriaca was sampled from a single individual at the Western

125 Illinois University research farm, raised from seed from a wild population in McDonough

126 County, Illinois $\left(40.29622^{\circ} \mathrm{N}, 90.89876^{\circ} \mathrm{W}\right.$; Winthrop B. Phippen s.n., OSC 226164, 226165).

127 DNA was extracted from frozen tissue using the FastDNA Spin Kit from MPBiomedicals (Santa 
128 Ana, CA, USA) following manufacturer's protocols, modified by the addition of $40 \mu \mathrm{L} 1 \%$

129 polyvinylpyrrolidone and $10 \mu \mathrm{L} \beta$-mercaptoethanol to the $1000 \mu \mathrm{L}$ lysis solution $(800 \mu \mathrm{L}$ CLS-

$130 \mathrm{VF}+200 \mu \mathrm{L}$ PPS) prior to grinding.

131 Aliquots of isolated DNA were sheared with a BioRuptor sonicator (Diagenode Inc.,

132 Denville, NJ, USA) at low power for 10 cycles of $30 \mathrm{~s}$ on/30 s off. Two libraries were prepared

133 using the Illumina Paired-End DNA Sample Prep Kit (catalog number PE-102-1001, Illumina

134 Inc., San Diego, CA, USA; Solexa, Inc, 2006). Ligated fragments were cut from agarose gels

135 centered around 225 bp and 450 bp, and were amplified through 15 and 14 cycles, respectively,

136 of polymerase chain reaction using Phusion High-Fidelity PCR Master Mix (New England

137 BioLabs, Ipswich, MA, USA) and standard Illumina primers. Cleaned product was submitted for

138 sequencing on an Illumina GAII Sequencer at the Center for Genome Research and

139 Biocomputing (CGRB) at Oregon State University (Corvallis, OR, USA). One lane of the 450 bp

140 library was sequenced with 80 bp paired-end reads, and 5 lanes of the 225 bp library were

141 sequenced with 120 bp paired-end reads.

142 Frozen tissue of the sequenced individual was sent to GlobalBiologics, LLC (Columbia,

143 MO, USA) for DNA extraction and production of mate-pair libraries using the Illumina Mate Pair

144 Library v2 protocol with average insert sizes of $2750 \mathrm{bp}$ and $3500 \mathrm{bp}$, and indexed with unique

145 barcode sequences (Bioo Scientific, Austin, TX, USA). The 2750 bp library was sequenced with

146101 bp paired-end reads on an Illumina HiSeq 2000 sequencer at the CGRB, on the same lane as

147 two other samples from unrelated projects. The 3500 bp library was sequenced on an Illumina

148 MiSeq at Oregon Health and Science University (Portland, OR, USA) with 33 bp paired-end

149 reads (Table 2). Purified DNA of that same individual was also provided to the CGRB for

150 production of a mate-pair library using the Illumina Nextera protocol with an average insert size

151 of 2000 bp. This library was sequenced with 76 bp paired-end reads on an Illumina MiSeq at the

152 CGRB, along with 14 other samples from unrelated projects (Table 2). 
153 Genomic read processing

Read pools were evaluated for quality parameters using FastQC (Andrews, 2010). Pairs of

155 reads properly mapping to the Asclepias chloroplast or mitochondria, with three or fewer

156 mismatches between the target and query, were filtered out using Bowtie 2 v. 2.1.0 (scoring

157 parameter “--score-min L,-6,0”), samtools v. 0.1.18, and bamtools v. 2.3.0 (Li et al., 2009;

158 Langmead \& Salzberg, 2012; Barnett et al., 2013). Portions of reads matching the Illumina

159 adapter sequences were removed with Trimmomatic v. 0.30 and the "ILLUMINACLIP:TruSeq2-

160 PE.fa:2:30:10” option (Bolger, Lohse \& Usadel, 2014). Duplicate read pairs from the same

161 library were removed using the custom script fastq_collapse.py (Weitemier, 2014). Paired-end

162 read pairs with sequences that overlapped by $\geq 7$ bp sharing $\geq 90 \%$ identity were merged using the

163 program FLASH v. 1.2.6 (parameters “-m 7 -M 80 -x 0.10”) (Magoč \& Salzberg, 2011). The 3'

164 and 5' ends of reads were then trimmed of any bases with a Phred quality score below 30, and any

165 remaining reads less than 30 bp were removed using Trimmomatic command "LEADING:30

166 TRAILING:30 MINLEN:30”.

167 Summary statistics were calculated using a k-mer distribution plot of reads from the 225

168 bp insert library after removing chloroplast and mitochondrial reads, but prior to joining with

169 FLASH. K-mers of 17 bp were counted using BBTools script kmercountexact.sh, and estimates

170 of genome size and heterozygosity were calculated using the program gce (Liu et al., 2013;

171 Bushnell \& Rood, 2015).

172 RNA-seq library preparation, sequencing, and assembly

173 Total RNA was extracted from the individual used for genome sequencing from leaves

174 and buds separately, by homogenizing approximately $200 \mathrm{mg}$ of fresh frozen tissue on dry ice in

175 a Fast-Prep-24 bead mill. Cold extraction buffer (1.5 mL of 3M LiCl/8M urea; 1\% PVP K-60;

176 0.1M dithiothreitol; Tai, Pelletier \& Beardmore, 2004) was added to the ground tissue. Tissue was

177 then homogenized and cellular debris pelleted at $200 \times g$ for 10 minutes at $4^{\circ} \mathrm{C}$. Supernatant was 
178 incubated at $4^{\circ} \mathrm{C}$ overnight. RNA was pelleted by centrifugation $(20,000 \times g$ for 30 minutes at

$1794^{\circ} \mathrm{C}$ ) and cleaned using a ZR Plant RNA MiniPrep kit (Zymo Research, Irvine, CA, USA). The

180 integrity of the extracted RNA was assessed using an Agilent 2100 Bioanalyzer (Agilent

181 Technologies, SantaClara, CA, USA); extractions from both tissues showed RIN values greater

182 than 8.0. For each tissue type, an RNA-seq library was prepared using the Illumina RNA-Seq

183 TruSeq kit v. 2.0 with the modifications of Parkhomchuk et al. (2009) to allow strand-specific

184 sequencing by dUTP incorporation.

185 Libraries were sequenced on an Illumina HiSeq 2000 at the CGRB to yield 101 bp single-

186 end reads. Before further analysis, reads that did not pass the Illumina chastity and purity filters

187 were removed. Trimmomatic 0.20 (Bolger, Lohse \& Usadel, 2014) was used to trim the final base

188 of each read, leading and trailing bases with quality scores below Q20, and all following bases if

189 a sliding window of 5 bp did not have an average quality of at least Q30. Reads shorter than 36

190 bp after trimming were excluded (Trimmomatic command “CROP:100 LEADING:20

191 TRAILING:20 SLIDINGWINDOW:5:30 MINLEN:36”).

192 Transcripts were assembled de novo using Trinity (Release 2013-08-14) (Grabherr et al.,

193 2011) for bud and leaf reads separately, as well as combined into a single data set using default

194 settings, except for using a minimum contig length of $101 \mathrm{bp}$. The same settings were also used

195 to assemble RNA-seq data from leaf tissue of the same A. syriaca individual from a library made

196 using ribosomal RNA subtraction (Straub et al., 2013). Best-scoring open reading frames (ORFs)

197 were determined for each library based on attributes including length, reading frame, and

198 nucleotide composition using the TransDecoder utility provided with Trinity (Haas et al., 2013).

199 Transcripts were annotated using Mercator (Lohse et al., 2014) and TRAPID (Van Bel et al.,

200 2013). The Mercator analysis was conducted with default options, with the exception of not

201 allowing multiple bin assignments. Therefore multiple databases, including UniProt, were used in

202 annotation. The TRAPID annotations were based on the Plaza 2.5 reference database (Van Bel et 
203 al., 2012), and the similarity search was restricted to the eudicot clade with an E-value cutoff of

$20410 \mathrm{e}^{-5}$. Functional annotations were added to transcripts based on both gene family and best

205 database hit.

206 Comparative transcriptome and gene family evolution analyses in Apocynaceae

207 For a comparative analysis, transcriptomes were obtained for five other species of

208 Apocynaceae. Catharanthus roseus and Rauvolfia serpentina transcriptomes were downloaded

209 from the Medicinal Plant Genomics Resource project database

210 (http://medicinalplantgenomics.msu.edu; Góngora-Castillo et al., 2012b), the Rhazya stricta

211 (GenBank GAMW01000000; Yates et al., 2014) and Calotropis procera (GenBank

212 GBHG01000000; Kwon et al., 2015) transcriptomes were downloaded from NCBI, and the

213 Tabernaemontana elegans transcriptome was downloaded from the PhytoMetaSyn Project

214 database (www.phytometasyn.ca; Xiao et al., 2013). All transcriptomes, including that of $A$.

215 syriaca, were checked for duplicate transcripts, and the duplicates removed using the Dedupe tool

216 in BBMap (Bushnell \& Rood, 2015). Transcriptomes were checked for completeness using

217 BUSCO v. 1.22 (Simão et al., 2015). Transcripts of all species were assigned to reference gene

218 families using TRAPID. Reference gene family assignments were obtained from two high quality

219 genomes, Coffea canephora (Denoeud et al., 2014) and Vitis vinifera (PLAZA v. 2.5; Proost et

220 al., 2009).

221 A phylogenetic framework for comparative analysis was produced using published

222 evolutionary relationships and divergence times in Apocynaceae (Fishbein et al., 2018). The

223 timings of the Coffea split from Apocynaceae and the Vitis split from Gentianales were based on

224 the estimates of Wikström et al. (2015). In order to examine changes in gene family sizes across

225 Apocynaceae transcriptomes, BadiRate v. 1.35 (Librado, Vieira \& Rozas, 2012) was run using the

226 BDI (birth-death-innovation) stochastic model with a free rate (FR) branch model where each 
227 branch can have a different gene turn-over rate. Gains and losses were inferred using Wagner

228 (ordered) parsimony (Kluge \& Farris, 1969).

229 Genomic sequence assembly

230 Processed read-pairs were assembled into contigs using Platanus v. 1.2.1 (Kajitani et al.,

231 2014). Platanus is designed to assemble highly heterozygous diploid genomes, and initially uses

232 several k-mer sizes during assembly. Asclepias reads were assembled with an initial k-mer size of

23325 bp with a k-mer step increase of 10 bp up to a maximum k-mer of $110 \mathrm{bp}$. As part of the

234 expectation for heterozygous assembly, Platanus can merge contigs sharing high identity. We

235 allowed contigs sharing 85\% identity to be merged (assembly parameters “-k 25 -u 0.15”).

236 Scaffolding was performed with Platanus, setting the paired-end reads as "inward

237 pointing” reads and the mate-pair reads as “outward pointing” reads. Reads were mapped to

238 scaffolds using an initial seed size of $21 \mathrm{bp}$, one link between contigs was sufficient to align them

239 into a scaffold, and scaffolds sharing 85\% identity could be merged (scaffolding parameters “-s

24021 -l 1 -u 0.15”).

241 Gaps between scaffolds were closed via local alignment and assembly of reads around the

242 gaps using Platanus. An initial seed size of 21 bp was used to include reads in the mapping

243 around a gap, and a minimum overlap of 21 bp between the newly assembled filler contig and the

244 edges of the scaffold was required to use that contig to fill the gap (gap close parameters “-s 21 -k

24521 -vd 21 -vo 21”).

246 Transcripts were mapped to Asclepias scaffolds $\geq 1$ kbp using BLAT v. 32x1; one or more

247 transcripts spanning multiple scaffolds were used to merge those scaffolds (Kent, 2002). This was

248 performed with the program Scubat (<https://github.com/elswob/SCUBAT $>$ accessed

249 12/17/2015) modified so that scaffolds would not be clipped when joined by cap3 v. 02/10/15

250 (Huang \& Madan, 1999; Tange, 2011; Elsworth, 2012). 
251 Contaminant removal

252 Merged scaffolds were compared against a genomic database of potentially contaminating

253 organisms with the program DeconSeq standalone v. 0.4.3 (Schmieder \& Edwards, 2011).

254 Contaminant databases were downloaded from the DeconSeq website representing bacteria,

255 archaea, viruses, 18S rRNA, zebrafish, mouse, and several human genomes

256 (<http://deconseq.sourceforge.net $>$ accessed January 20, 2016). Fungal genomes were obtained

257 from the National Center for Biotechnology Information (NCBI) including Alternaria

258 arborescens accession AIIC01, Aspergillus fumigatus AAHF01, Bipolaris maydis AIHU01,

259 Botrytis cinerea assembly GCA_000832945.1, Cladosprium sphaerospermum AIIA02,

260 Fomitopsis pinicola AEHC02, Fusarium oxysporum AAXH01, Galerina marginata AYUM01,

261 Hypoxylon sp. JYCQ01, Penicillium expansum AYHP01, Rhodotorula graminis JTAO01,

262 Saccharomyces cerevisiae assembly GCA_000146045.2, and Trichoderma reesei AAIL02

263 (Goffeau et al., 1997; Nierman et al., 2005; Martinez et al., 2008; Ma et al., 2010; Amselem et al.,

264 2011; Hu et al., 2012; Ohm et al., 2012; Ng et al., 2012; Floudas et al., 2012; Riley et al., 2014;

265 Firrincieli et al., 2015; Shaw et al., 2015; Li et al., 2015). The genome of Solanum lycopersicum

266 (ITAG 2.4) was downloaded from the Sol Genomics Network (The Tomato Genome Consortium,

267 2012). The fungal and Solanum genomes were prepared as DeconSeq databases following the

268 DeconSeq website, including filtering of repeated Ns, removal of duplicate sequences, and

269 indexing with a custom version of BWA released with DeconSeq (Li \& Durbin, 2010;

$270<$ http://deconseq.sourceforge.net> accessed January 20, 2016).

271 Genomes obtained from the DeconSeq website and the fungal genomes were used as

272 contaminant databases, the Solanum genome was used as a retain database. Scaffolds matching

273 one of the contaminant genomes with $\geq 80 \%$ identity along $\geq 80 \%$ of the scaffold length were

274 excluded as contaminants. Those scaffolds matching both a contaminating genome and the

275 Solanum genome were retained. 
276

277

278

279

280

281

282

283

284

285

286

287

288

289

290

291

292

293

294

295

296

297

298

299

300

\section{Gene prediction and annotation}

A library of Asclepias repetitive elements was created following guidelines in the MAKER Genome Annotation Pipeline online documentation (Jiang, 2015). The program

RepeatModeler v. open-1.0.8 was used to integrate the programs RepeatMasker v. open-4.0.5, rmblastn v. 2.2.28, RECON v. 1.08, Tandem Repeats Finder v. 4.07b, and RepeatScout v. 1.0.5 (Benson, 1999; Bao \& Eddy, 2002; Price, Jones \& Pevzner, 2005; Smit, Hubley \& Green, 2015).

Repeat models initially missing a repeat annotation were compared, using BLAT, against a library of class I and class II transposable elements acquired from the TESeeker website (Kennedy et al., 2010, 2011), and matching sequences provided an annotation. Remaining unannotated models were submitted to the online repeat analysis tool, CENSOR, and provided annotations with a score $\geq 400$ and $\geq 50 \%$ sequence similarity (Kohany et al., 2006). A set of proteins from Arabidopsis thaliana was filtered to remove proteins from transposable elements, then compared using BLASTX against the Asclepias repeat models. The program ProtExcluder.pl v. 1.1 then used the BLASTX output to remove repeat models and flanking regions matching Arabidopsis proteins (Altschul et al., 1990; Jiang, 2015).

The set of scaffolds $\geq 1 \mathrm{kbp}$ were annotated via the online annotation and curation tool GenSAS v. 4.0 (Lee et al., 2011; Humann et al., 2016), which was used to implement the following tools for repeat masking, transcript and protein mapping, ab initio gene prediction, gene consensus creation, and mapping of Asclepias predicted proteins:

1) Repeats in the assembled sequence were masked via RepeatMasker v. open-4.0.1 using the Asclepias repeat models and using models developed from dicots more broadly (Smit, Hubley \& Green, 2015).

2) Multiple datasets were mapped onto Asclepias scaffolds in order to assist with gene prediction. The best-scoring ORFs from assembled Asclepias transcripts were mapped using both BLAT and BLAST (expect < 1e-50, 99\% identity). Assembled transcripts from Calotropis 
301 procera were mapped with BLAT (Kwon et al., 2015). Proteins from Coffea canephora were

302 mapped with BLASTX (e<0.0001; Denoeud et al., 2014). While additional high-quality genomes

303 within Apocynaceae were later released (Sabir et al., 2016; Hoopes et al., 2017), they were not

304 available at the time this work was performed.

305 3) Genes were predicted using the ab initio tools Augustus v. 3.1.0, SNAP, and PASA

306 (Haas et al., 2003; Korf, 2004; Stanke et al., 2008). Augustus was run using gene models from

307 Solanum, finding genes on both strands, and allowing partial models; SNAP was run using

308 models from Arabidopsis thaliana. PASA was informed by the best-scoring ORFs from

309 assembled Asclepias transcripts.

310 4) Multiple lines of evidence were integrated into a gene consensus using

311 EVidenceModeler (Haas et al., 2008) with the following weights: Augustus, 1; SNAP, 1; Coffea

312 proteins, 5; Asclepias transcripts (BLAST), 7; Asclepias transcripts (BLAT), 7; Calotropis

313 transcripts, 5; PASA, 7. Consensus gene models were then refined using PASA, again informed

314 by Asclepias transcripts.

315 5) Predicted proteins were compared to the NCBI plant RefSeq database using BLASTP

316 (expect < 1e-4, BLOSUM62 matrix; Pruitt et al., 2002), as well as being mapped against protein

317 sequences from Coffea and Catharanthus roseus (expect < 1e-4; Denoeud et al., 2014; Kellner et

318 al., 2015). Protein families were classified using the InterPro database and InterProScan v. 5.8-

31949.0 (Jones et al., 2014; Mitchell et al., 2015). Transfer RNAs were identified using tRNAscan-

320 SE v. 1.3.1 (Lowe \& Eddy, 1997). Additional open reading frames were found using the getorf

321 tool from the EMBOSS suite, accepting a minimum of 30 bp (Rice, Longden \& Bleasby, 2000).

322 Some predicted proteins were missing one or more exons, either because they were

323 fragmented on the ends of scaffolds or, rarely, transcript evidence predicted exons with non-

324 canonical splice sites. The predicted coding sequence produced by GenSas for some of these 
325 proteins was out of frame. In these cases the coding sequence was translated under all reading

326 frames and a translation lacking internal stop codons was selected, if available.

327 An estimate of the completeness of the assembled gene space was calculated using the

328 program BUSCO v. 1.22 and a set of 956 conserved single copy plant genes (Simão et al., 2015).

329 BUSCO was run independently on the set of coding sequences returned following gene

330 prediction as well as on the assembled scaffolds $\geq 1 \mathrm{kbp}$ using Augustus gene prediction with

331 Solanum models. Predicted genes from Asclepias, Catharanthus, Coffea, and Vitis (obtained from

332 the PLAZA 3.0 database) were clustered into orthogroups using OrthoFinder v. 0.7.1 (The

333 French-Italian Public Consortium for Grapevine Genome Characterization, 2007; Emms \& Kelly,

334 2015; Proost et al., 2015).

335 Gene analyses

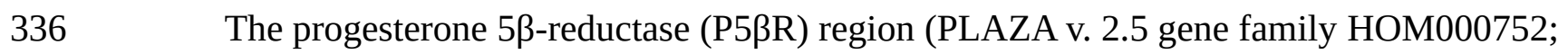

337 InterPro NAD(P)-binding domain IPR016040; Gene Ontology: coenzyme binding GO:0050662,

338 catalytic activity GO:0003824) was identified in assembled scaffolds with BLAT (Kent, 2002),

339 using the P5ßR sequences from Asclepias curassavica (ADG56538; Bauer et al., 2010) and

340 Catharanthus roseus (KJ873882-KJ873887; Munkert et al., 2015) as references. A maximum

341 likelihood tree was constructed from peptide sequences of two A. syriaca regions with high

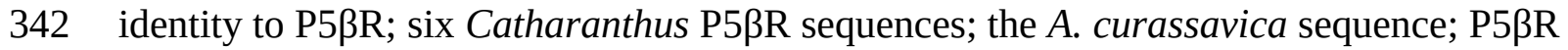

343 sequences from Calotropis procera (Kwon et al., 2015), C. gigantea (Hoopes et al., 2017), and

344 Rhazya stricta (Sabir et al., 2016); sequences from Digitalis purpurea and D. lantata

345 (ACZ66261, AAS76634), representing P5ßR2 and P5ßR paralogs, respectively; and a sequence

346 from Picea sitchensis (ABK24388). P5ßR sequence alignments were performed using MUSCLE

347 3.8.425, as implemented in Geneious v. 11.1.5, with a maximum of 10 iterations (Edgar, 2004;

348 Kearse et al., 2012). The optimal models of amino acid substitution, rate variation among sites,

349 and equilibrium frequencies were inferred using the Akaike and Bayesian information criteria, as 
350 implemented in the online tool PhyML 3.0, which was also used to infer trees under those models

351 and calculate aBayes support values (Guindon \& Gascuel, 2003; Guindon et al., 2010; Anisimova

352 et al., 2011).

\section{SNP finding and targeted enrichment probe development}

354 The Platanus genome assembler uses a de Bruijn graph approach for contig assembly

355 (Kajitani et al., 2014). Certain types of branches in this graph, known as “bubbles,” may be

356 caused by heterozygosity and are saved by the program for use in later assembly stages. Here,

357 saved bubbles were filtered to identify those likely to represent heterozygous sites in low-copy

358 regions of the genome.

359 The program CD-HIT-EST v. 4.5 .4 was used to cluster any bubbles sharing $\geq 90 \%$

360 identity, which were removed, leaving only unique bubbles (Li \& Godzik, 2006). Unique bubbles

361 were mapped against the set of Asclepias scaffolds $\geq 1 \mathrm{kbp}$ using BLAT at minimum identity

362 thresholds of $90 \%$ and 95\% (Kent, 2002). A set of 4000 SNP probes developed from a

363 preliminary study using a similar approach, but from a different genome assembly, were mapped

364 against the assembly presented here with a 90\% identity threshold (Weitemier et al., 2014). One

365 appropriate bubble from each scaffold $<10 \mathrm{kbp}$, and up to two bubbles from scaffolds $\geq 10 \mathrm{kbp}$,

366 were selected, up to a total of 20,000 bubbles. Bubbles mapping only once within the $\geq 90 \%$

367 identity mapping analysis were selected first, progressively adding bubbles that either mapped to

$368 \leq 4$ locations in the $\geq 90 \%$ identity mapping or mapped to $\leq 3$ locations in the $\geq 95 \%$ identity

369 mapping. Bubble sequences were trimmed to $80 \mathrm{bp}$, and centered around the SNP site where

370 possible. Potential SNP probes were further analyzed by MYcroarray (now Arbor BioSciences,

371 Ann Arbor, MI, USA) and excluded if they were predicted to anneal in a solution hybridization

372 reaction to $>10$ locations within the Asclepias genome at $62.5-65^{\circ} \mathrm{C}$ or $>2$ locations above $65^{\circ} \mathrm{C}$.

373 Twenty thousand RNA oligos suitable for targeted enrichment, matching 17,684 scaffolds, were 
374 produced by MYcroarray. RNA oligo sequences are available in the supplemental data set

375 (Weitemier, 2017).

\section{$376 \quad$ Linkage mapping population}

Mature follicles were collected from the open pollinated plant that was the subject of

plant (1, 3, 1, and 1 follicle per stem) were germinated and grown at Oklahoma State University.

Due to the pollination system of Asclepias, seeds in a fruit are likely to be fertilized by a single

parents are represented among the 96 mapping offspring.

testa was nicked opposite from the micropylar end and the seeds germinated on moist filter paper,

2-3 cm. Seedlings were again transplanted to 3-inch deep pots following the expansion to two

environment chamber at $14 \mathrm{hr}$ daylength at approximately $27^{\circ} \mathrm{C}$. Plants were grown for approximately 90 days, harvested, and rinsed in distilled water, and frozen at $-80^{\circ} \mathrm{C}$. DNA was extracted from roots, shoots, or a combination of roots and shoots using the FastDNA ${ }^{\circledR}$ kit (MP

393 (Thermo Scientific, Waltham, MA, USA). DNA quantity and quality were visualized using

394 agarose gel electrophoresis and quantified with a Qubit ${ }^{\circledR}$ fluorometer (Invitrogen, Carlsbad, CA, USA) and Quant-iT ${ }^{\mathrm{TM}}$ DNA-BR Assay Kit. 
399 cycles to achieve a high concentration of fragments at the target size of 300-400 bp. Illumina-

400 compatible, dual-indexed libraries were produced with the TruSeq ${ }^{\circledR}$ HT kit (Illumina), each with a

401 unique barcode.

402 Barcoded libraries were pooled by equal DNA mass in three groups of 32 samples. These

403 were enriched for targeted SNP regions using RNA oligos and following MYcroarray MYbaits

404 protocol v. 3.00. Enriched pools were then themselves evenly pooled and sequenced with $150 \mathrm{bp}$

405 paired-end reads on an Illumina HiSeq 3000 at the CGRB, producing $120.3 \mathrm{Mbp}$ of sequence

406 data (NCBI short read archive: SRX2163716-SRX2163811).

407 Linkage analyses

408 Reads from the 96 target-enriched offspring libraries were processed using Trimmomatic

409 v. 0.33 to remove adapter sequences, bases on the ends of reads with a Phred quality score below

410 three, and clipping once a sliding window of 4 bp fell below an average quality score of 17

411 (Bolger, Lohse \& Usadel, 2014). Processed reads for 90 samples (excluding 6 with low

412 sequencing depth) were mapped onto the assembled scaffolds using bowtie2 with "sensitive"

413 settings and a maximum fragment length of 600 bp (Langmead \& Salzberg, 2012). Reads from

414 the 225 bp insert library of the sequenced individual were also mapped back onto assembled

415 scaffolds using the same settings. Mappings for all individuals and the parent were combined

416 using samtools v. 0.1.16 with the samtools "mpileup" command and flags “-D -S" to record the

417 per-sample read depth and strand-specific bias. SNP positions were called using the bcftools

418 “view” command with flags “-v -c -g” to output only potential variant sites with called genotypes

419 (Li et al., 2009).

420 Two subsets of SNPs were retained. The first was a subset of SNPs where the maternal

421 parent was heterozygous and the paternal parents for all offspring were homozygous for the same

422 allele. The file containing all variants was converted to a format suitable for the R package

423 OneMap, using a custom perl script (Tennessen, 2015), retaining only sites heterozygous in one 
424 parent, the maternal sequenced individual. In this filtering the minor genotype abundance (either

425 heterozygote or homozygote) needed to be at least 24 across 90 samples, loci could have up to

$42630 \%$ missing individuals, and alternative genotypes within individuals were ignored if their Phred

427 probability score was 15 or above (i.e., of the three possible genotypes AA, Aa, aa, one should be

428 most probable with a low Phred score and the other two less probable with Phred scores above 429 15).

The second subset retained SNPs from 22 full siblings (from the fruit producing the most

431 offspring) for loci in which either the maternal or paternal parent, but not both, were

432 heterozygous. Filtering in this set required a minor genotype abundance of at least five, loci could

433 have up to four missing individuals, and genotypes with Phred probabilities of 20 or above were

434 ignored (i.e., the final genotype calls are more certain because alternative genotypes are less

435 likely).

436 SNP sets were clustered into linkage groups in R v. 3.2.2 using the package OneMap v.

437 2.0-4 (Margarido, Souza \& Garcia, 2007; R Core Team, 2014). One SNP from each scaffold was

438 selected from SNPs among the full set of individuals, and were grouped using a logarithm of

439 odds (LOD) threshold of 8.4. This clustered SNP loci into eleven clear groups, referred to here as

440 the core linkage groups.

441 From the full-sibling set of SNPs, those held on the same scaffold and with identical

442 genotypes across individuals (i.e., in perfect linkage) were grouped, and SNPs on different

443 scaffolds in perfect linkage with no missing data were grouped. This was performed separately

444 for loci where either the maternal or paternal parent was heterozygous. These loci were clustered

445 into groups using LOD scores 6.1, 6.0, and 5.5. Each of these groupings produced hundreds of

446 groups, but each contained about 22 groups that were substantially larger than the others.

447 A custom R script was used to combine the linkage group identity of scaffolds in the core 448 linkage groups with scaffolds and groups in the sibling sets (Weitemier, 2017). For example, 
449 scaffold A could be assigned to a linkage group if it was in perfect linkage in the sibling set with

450 scaffold B, and scaffold B was also present in the core linkage groups. If multiple scaffolds were

451 perfectly linked, but associated with different core linkage groups, no unknown scaffolds would

452 be assigned unless the most common core linkage group was three times as common as the next

453 core group.

454 Linkage groupings in the sibling sets could be assigned to core linkage groups based on

455 the membership of the scaffolds they contained. If the markers indicating that a sibling group

456 should belong to a certain core linkage group were ten times as common as markers supporting a

457 second most common assignment, then the sibling group was assigned to the core group, and all

458 unknown scaffolds it contained also assigned to that group. (For example, sibling group A

459 contains ten scaffolds known to be on core linkage group 1, one scaffold known to be on core

460 linkage group 2, and one unknown scaffold; sibling group A is assigned to core linkage group 1

461 and the unknown scaffold is similarly assigned.)

462 This process was performed iteratively, progressively assigning scaffolds to core linkage

463 groups. It was performed first with the sibling set grouped with LOD 6.1, then the grouping with

464 LOD 6.0, finally the grouping with LOD 5.5.

465 Synteny within Gentianales

466 Scaffolds found within the core linkage groups were mapped to Coffea coding sequences

467 (BLASTN, expect $<1$, best hit chosen) and mapped to their location on Coffea

468 pseudochromosomes. Six Asclepias linkage groups had a roughly one-to-one correspondence

469 with a Coffea pseudochromosome (e.g., most of the scaffolds from that linkage group, and few

470 from other linkage groups, mapped to the pseudochromosome). From these six linkage groups

471 one marker was selected for every $1 \mathrm{Mbp}$ segment of the Coffea chromosome. Recombination

472 fractions were measured among these loci using OneMap (retaining "safe” markers with

473 THRES=5) and converted to cM using the Kosambi mapping function. 
474 RESULTS

475 Sequencing and read processing

$476 \quad$ Paired-end sequencing produced 215.6 million pairs of reads representing $50.0 \mathrm{Gbp}$ of

477 sequence data, and mate-pair sequencing produced 52.8 million pairs of reads for $9.9 \mathrm{Gbp}$ of

478 sequence data. After read filtering and processing, $30.7 \mathrm{Gbp}$ of paired-end sequence data

479 remained along with $3.0 \mathrm{Gbp}$ of mate-pair data. This represents total average sequence coverage

480 of $80.4 \times$ on the $420 \mathrm{Mbp}$ Asclepias syriaca genome (Table 2).

481 The distribution of $17 \mathrm{bp} \mathrm{k-mers} \mathrm{from} \mathrm{the} \mathrm{largest} \mathrm{set} \mathrm{of} \mathrm{paired-end} \mathrm{reads} \mathrm{demonstrates} \mathrm{a}$

482 clear bi-modal distribution, with peaks at $43 \times$ and $84 \times$ depth (Fig. S1), corresponding to the

483 sequencing depth of heterozygous and homozygous portions of the genome, respectively. This k-

484 mer distribution provides a genome size estimate of $406 \mathrm{Mbp}$, and a site heterozygosity rate

485 estimate of 0.056 .

486 Sequence assembly and gene annotation

The assembly of Asclepias syriaca contains 54,266 scaffolds $\geq 1$ kbp, with N50 = 3415 bp, 488 representing 37\% of the estimated genome (156.6 Mbp of sequence plus 5.8 Mbp of gaps, Table

3). When including scaffolds $\geq 200 \mathrm{bp}$ the assembly sums to $229.7 \mathrm{Mbp}$, with N50 $=1904 \mathrm{bp}$. The

490 largest scaffold is $100 \mathrm{kbp}$, and $10 \%$ of the Asclepias genome, $42.82 \mathrm{Mbp}$, is held on 2343

491 scaffolds $\geq 10 \mathrm{kbp}$. Prior to scaffolding, gap closing, contaminant removal, and transcript-assisted

492 scaffolding, the initial assembly produced 2.8 million contigs, with 848,509 $\geq 200$ bp and 38,615

$493 \geq 1 \mathrm{kbp}$. Initial contigs $\geq 1 \mathrm{kbp}$ summed to $74.9 \mathrm{Mbp}$ with N50 = $2041 \mathrm{bp}$, and the largest contig

494 was $16 \mathrm{kbp}$.

495

Within the $156.6 \mathrm{Mbp}$ of scaffolds $\geq 1 \mathrm{kbp}, 1.25$ million putative open reading frames

496 were identified, along with 193 transfer RNA loci. Assembled repeat elements made up about

$49775.7 \mathrm{Mbp}$. A total of 14,474 protein-coding genes were identified based on transcript evidence,

498 closely related proteins, and ab initio models. These are predicted to produce 15,628 unique 
499 mRNAs, and are made up of a total of 87,496 exons with an average length of $225.3 \mathrm{bp}$. The

500 median length of predicted proteins is 303 amino acids (mean $=402$ ), which is shorter than

501 lengths predicted in Calotropis (median $=367$, mean $=448$ ), similar to those predicted in Coffea

502 (median $=334$, mean $=402)$, but longer than those predicted in Catharanthus $($ median $=251$,

503 mean = 340; Fig. 2). Of the 14,474 predicted genes, 13,749 (95.0\%) mapped to either Coffea or

504 Catharanthus proteins, and 9811 mapped to RefSeq proteins.

505 Assembly of the Asclepias transcriptome produced 32,728 best-scoring ORFs, ranging

506 from 300 - 13,005 bp, with N50 = 1422 bp, and summing to 37.4 Mbp. Of these, 31,654 (96.7\%)

507 mapped onto scaffolds $\geq 1 \mathrm{kbp}$. For Calotropis, 92,115 (88.4\%) transcripts were mapped to

508 Asclepias scaffolds, while 23,182 (90.6\%) proteins from Coffea mapped to the assembly. BUSCO

509 analysis of the genome assembly identified 895 of the 956 plant genes in its set (93.6\%). Of

510 these, 209 were identified as duplicates and another 77 genes were fragmented, meaning they

511 were found in the genome assembly, but with a length outside two standard deviations of the

512 mean BUSCO length for that gene. When applied to just the set of coding sequences BUSCO

513 identified 742 complete genes (302 duplicated) and 84 fragmented genes, representing 86.4\% of

514 the conserved plant gene set. Apocynaceae transcriptomes were compared using the BUSCO set

515 of 429 genes common to eukaryotes. The Asclepias transcriptome contained 365 of the genes

516 (117 duplicated, 21 fragmented), representing 85.1\%. Presence of these genes in other

517 transcriptomes (Catharanthus, Rauvolfia, Rhazya, Tabernaemontana, Calotropis) ranged from

518 83.7\% in Calotropis to 86.5\% in Tabernaemontana, indicating that the Asclepias transcriptome

519 assembly was of similar completeness to Apocynaceae transcriptomes publically available at the

520 time of analysis. All Apocynaceae transcriptomes showed increased duplication of the 429 genes

521 with approximately $2 \times$ the number of duplicates on average compared to the Coffea,

522 Catharanthus, and Vitis genomes. 
524 were clustered into 13,906 orthogroups. Asclepias had the highest percentage of genes placed in

525 orthogroups, 81.6\%, but those genes only represent 9837 orthogroups, the lowest of the four

526 genomes. Asclepias shared the fewest orthogroups with other species (Table S1).

527 Comparison of all six Apocynaceae transcriptomes showed 5195 gene families were

528 common to all. The Asclepias transcriptome contained 5762 gene families also present in the

529 Coffea genome. There were 58 gene families with 1-3 gene copies in Asclepias that were not

530 present in other Apocynaceae. Among Apocynaceae lineages, Asclepias was not unusual in its

531 number of gene gains or losses based on the BadiRate analysis. Asclepias had close to the median

532 number of gene gains among all lineages with 5697 (median $=5791.5$ ), much less than the

53315,831 gene gains inferred in the lineage with the highest number of gains, Rauvolfia. Similarly,

534 the number of gene losses in Asclepias at 905 was just below the median number of losses

535 (median = 1136), and much less than the 7619 losses inferred for Catharanthus. While Asclepias

536 had one of the highest gene birth rates over time (0.01082 events per gene per million years; Fig.

537 3), it was lower than that of close relative Calotropis (0.01463 events per gene per million years),

538 and the rate inferred for the Rauvolfia plus Catharanthus plus Tabernaemontana lineage (0.14406

539 events per gene per million years) was an order of magnitude greater. Asclepias had close to the

540 median value for gene death rate (0.00177 events per gene per million years). However,

541 Asclepias had the second highest gene innovation rate (0.00069 events per gene per million

542 years) compared to other lineages (Fig. 3). As with gene birth rate, the gene innovation rate of the

543 Rauvolfia plus Catharanthus plus Tabernaemontana lineage (0.00146 events per gene per million

544 years) was an order of magnitude higher.

545 Linkage mapping and synteny within Gentianales

546 Following filtering, the set of all 96 offspring retained over 16,000 SNPs for which the

547 maternal parent was heterozygous and all the paternal parents were homozygous for the same 
548 allele. These were located on 8495 scaffolds, covering 43.5 Mbp. Ninety of 96 individuals were

549 sequenced at adequate depth to inform linkage group analyses. At a likelihood of odds (LOD)

550 score of 8.4, 7809 scaffolds were clustered into 11 groups, the core linkage groups, representing

$55141.9 \mathrm{Mbp}$.

552 Filtering for SNPs among just the largest group of full-siblings, in which one parent (but

553 not both) was heterozygous, found 83,854 SNPs on 18,333 scaffolds. These SNPs were

554 consolidated by perfect linkage and then clustered at LOD scores of 6.1, 6.0, and 5.5. Combining

555 scaffolds from the core linkage groups with those clustered among the full-sibling group

556 ultimately provided a combined linkage set, with linkage group assignments to 16,285 scaffolds,

557 representing $75.0 \mathrm{Mbp}$.

558 Mapping of scaffolds from just the core linkage groups to Coffea pseudochromosomes

559 found several linkage group/pseudochromosome "best hit” pairs (e.g., most Asclepias scaffolds

560 from a linkage group mapped to one pseudochromosome, while few scaffolds from other linkage

561 groups mapped to that pseudochromosome). Asclepias linkage groups 2, 4, 6, 7, 8 and 9 mapped

562 in this manner to Coffea pseudochromosomes 10, 8, 6, 11, 3, and 1, respectively (Figs. 4, 5).

563 From these six linkage groups, SNPs were chosen mapping to every 1 Mbp region (if available)

564 of the corresponding Coffea pseudochromosome. Recombination distances were measured

565 among these markers and their relative positions within Asclepias plotted against their position in

566 Coffea (Figs. S2-S7). Monotonically increasing or decreasing series of points in these plots

567 represent loci in Asclepias and Coffea that maintain their relative positions. Several such marker

568 clusters are seen in these plots (e.g., Fig. S3), though they tend to cover only short chromosomal

569 regions and are often interrupted by markers from outside the cluster. 


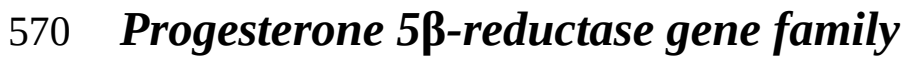

$571 \quad$ One region on linkage group 11 had $98.4 \%$ identity with peptide sequence from

572 progesterone $5 \beta$-reductase from Asclepias curassavica (Table S2). This region was supported by

573 A. syriaca transcriptome evidence, as well as mapped Calotropis transcripts and Coffea proteins.

574 Approximately 500 bp downstream from this gene, a second region was identified sharing $52 \%$

575 amino acid identity with the first region, for $70 \%$ of its length. The second region lacks transcript

576 evidence from A. syriaca, though portions of Calotropis transcripts and Coffea peptides map to it.

577 Gene predictions from Augustus and SNAP include potential exons within the region, and the

578 region includes P5 $\beta$ R conserved motifs I, II, and III, and portions of motifs IV, V, and VI

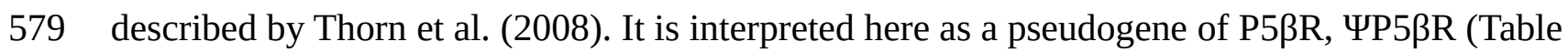

580 S2).

581

Paralogs of P5 $\beta \mathrm{R}$ have been described in other angiosperms including Arabidopsis,

582 Populus, Vitis, and Digitalis, and the P5 $\beta$ R2 paralog occurs on a chromosome separate from that

583 of P5ßR1 in Arabidopsis and Populus (Pérez-Bermúdez et al., 2010; Bauer et al., 2010). Due to

584 frame shifts and ambiguous exon boundaries in $\Psi P 5 \beta R$, it is difficult to assess the correct peptide

585 sequence it initially encoded, and therefore difficult to fully align with Digitalis P5 $\beta$ R1 and

586 P5 $\beta$ R2 sequences. However, a few motifs, particularly a triple tryptophan at the $\mathrm{N}$-terminal end

587 of the sequence, suggest its origin from P5 $\beta \mathrm{R} 1$, a conclusion supported by its position adjacent to

588 the coding P5ßR in Asclepias.

589 A third region on an unlinked scaffold exhibited moderate (37\%) identity with the peptide

590 sequence from linkage group 11 (Table S2). This region includes an intact reading frame and is

591 matched by transcripts from Calotropis, though a lack of Asclepias transcripts matching this

592 region indicates that it may not be regularly expressed within leaves or buds. A peptide alignment

593 was made for this sequence, the known coding P5 $\beta \mathrm{R}$ in Asclepias, and P5 $\beta \mathrm{R}$ sequences from $A$.

594 curassavica, Calotropis procera, C. gigantea, Rhazya, Digitalis, Catharanthus, and Picea to infer 
595 the phylogeny of this locus. The optimal model of sequence evolution selected by AIC was the

596 LG+G+I model of peptide substitution, rate variation among sites, and proportion of invariable

597 sites (BIC selected the LG+G model, but tree topologies were identical and are not shown). A

598 maximum-likelihood estimate of the P5ßR gene tree grouped the unlinked Asclepias sequence

599 with a paralog from Rhazya (originating on supercontig 3 from Sabir et al., 2016) and

600 Catharanthus paralog P5 $\beta$ R6 (Fig. 6). Together these are sister to all other P5 $\beta$ R sequences

601 analyzed, except Picea, which was used to root the gene tree. The P5 $\beta$ R sequence from linkage

602 group 11 is strongly supported as the most closely related sequence to the one from $A$.

603 curassavica, within a clade including P5ßR1 sequences from Digitalis and Catharanthus.

604 Analysis of the P5ßR gene family across Apocynaceae showed that this gene family is

605 largest in Rauvolfia, Catharanthus, and Tabernaemontana, with most of the expansion occurring

606 in the common ancestor of these three (Fig. 3). However, this interpretation may change as more

607 Apocynaceae genomes and transcriptomes become available.

\section{DISCUSSION}

609 The Asclepias syriaca nuclear genome assembly presented here represents a large fraction

610 of the protein-coding gene space, despite very high levels of heterozygosity and sequence data

611 restricted to Illumina short reads. Gene space coverage is supported by high proportions of

612 BUSCO plant core genes found within the assembly (93.6\%) as well as assembled transcripts

613 mapping to the assembly (96.7\%). A substantial portion of genes from related plant species

614 mapped to the assembly as well, including 88.4\% of transcripts from Calotropis and 90.6\% of

615 amino acid sequences from Coffea.

616 Overall, the Asclepias assembly is fragmented when compared to other plant genomes

617 assembled using either long reads or deep sequencing of known contiguous fragments (e.g. BACs

618 or fosmids), and inclusion of these technologies in future assembly efforts should result in a more

619 complete and contiguous assembly. Assembly was also hindered by poor quality mate-pair 
620 libraries containing low proportions of properly paired fragments (Table 2). However, assembly

621 results are typical for a sequencing project relying entirely on short reads, especially for

622 organisms with high levels of heterozygosity. For example, the Asclepias N50 value of $3.4 \mathrm{kbp}$

623 compares favorably to the assembly of the rubber tree, Hevea brasiliensis, genome (N50 = 2972

624 bp; Rahman et al., 2013), though it is not as contiguous as the dwarf birch, Betula nana, genome

625 (N50 = 18.6 kbp; Wang et al., 2012), which incorporated several mate pair libraries. The

626 assembly of the olive tree, Olea europaea, genome was also very similar to Asclepias, with N50

$627=3.8 \mathrm{kbp}$ prior to the inclusion of fosmid libraries (Cruz et al., 2016). However, paired-end and

628 mate-pair data for Calotropis gigantea provide an example of a less fragmented assembly from

629 similar data (N50 = 805 kbp, Table1; Hoopes et al., 2017). The effect of high heterozygosity is

630 clearly seen in the comparison of Asclepias and Catharanthus assemblies (Kellner et al., 2015).

631 While sequence data and genome assembly methods are similar between the two, Asclepias has

632 an estimated heterozygosity rate of $>1$ SNP per 20 bp, whereas the heterozygosity rate in the

633 inbred Catharanthus cultivar is estimated at <1 SNP per 1000 bp. This resulted in a N50 of 27.3

634 kbp assembled from only a single Catharanthus Illumina library (Table 1).

635 Functional annotations were applied to a high proportion (95.0\%) of the 14,474 called

636 genes, which were mapped to proteins from Catharanthus roseus and/or to Coffea canephora.

637 The number of called genes is well below the typical value for plant genomes: the genome of

638 Calotropis gigantea, the closest relative with an assembled genome, contains 19,536 gene loci

639 (Hoopes et al., 2017). The genomes of Rhazya and Catharanthus contain 21,164 and 33,829

640 called genes, respectively (Kellner et al., 2015; Sabir et al., 2016). The genome of Coffea

641 contains 25,574 protein-coding genes, and the genome of tomato, Solanum lycopersicum, from

642 the sister order, Solanales, contains 36,148 (The Tomato Genome Consortium, 2012; Denoeud et 643 al., 2014). 
645 fragmented genome assemblies (Denton et al., 2014), as indicated by the excess of short

646 predicted proteins relative to Coffea and Calotropis (Fig. 2). By contrast, the 14,474 called genes

647 in Asclepias is likely an underestimate of the true number. While the size distribution of predicted

648 Asclepias proteins is quite similar to that of Coffea, Asclepias contains fewer proteins of all sizes,

649 and the dramatic reduction of orthogroups found in Asclepias relative to other species argues for

650 deficiency in gene calling. While it's possible that similar genes were mistakenly collapsed into a

651 single contig during the assembly stage meant to collapse alleles at a single locus, this should

652 only occur with genes isolated on small contigs and should not affect the number of orthogroups

653 identified. Nevertheless, the high proportion of matches between the Asclepias genome assembly,

654 Asclepias transcripts, and gene sets from related organisms, indicates that the assembly likely

655 does contain sequence information for nearly the full complement of genes, but that some of

656 these have not been recognized by gene calling algorithms due to the fragmented nature of the

657 assembly.

658 Synteny within Gentianales

659 Eleven core linkage groups were produced from the set of SNPs originating from the

660 maternal parent, matching the expected number from a single parent with $x=n=11$ chromosomes.

661 Using full-siblings, a set of SNPs originating from either the maternal or paternal parent clustered

662 into hundreds of groups. Twenty-two of these were substantially larger than the others, matching

663 the expectation of 22 linkage groups originating from two $x=11$ parents.

664 Six of the eleven core linkage groups in Asclepias show high synteny at a chromosomal

665 scale with the pseudochromosomes of Coffea (Figs. 4, 5). This suggests that these chromosomes

666 have remained largely stable and retained the same gene content for over 95 Myr, throughout the

667 evolution of the Gentianales (Wikström et al., 2015). These stable chromosomes may have

668 remained largely intact for a much longer period as well. The stable Coffea pseudochromosomes 
$669(1,3,6,8,10$, and 11$)$ retain largely the same content as inferred for ancestral core eudicot

670 chromosomes, exhibiting little fractionation, even after an inferred genome triplication at the base

671 of the eudicots, 117-125 Myr ago (Jiao \& Paterson, 2014; see Figure 1B in Denoeud et al., 2014).

672 Despite the conservation of gene content, gene order within stable chromosomes may be

673 more labile. Plots of recombination distance among markers in Asclepias against physical

674 distance in Coffea show several sets of markers in Coffea that retain their relative order in

675 Asclepias, but are frequently interrupted by loci found elsewhere on the same Coffea

676 pseudochromosome. For example, within Asclepias linkage group 2 there is a set of markers that

677 retain their same relative ordering from positions 3 million to 8 million on Coffea

678 pseudochromosome 10 (Fig. S2). However, these markers in Asclepias are interrupted by markers

679 mapping to positions closer to the origin on the same Coffea pseudochromosome as well as a

680 marker mapping to the far end. The most conserved synteny is between Asclepias linkage group 8

681 and Coffea pseudochromosome 3, which show complete synteny except for an apparent

682 transposition of markers at positions 2 million and 7 million on Coffea pseudochromosome 3

683 (Fig. S3).

684 Contrasting the stability in gene content of six Coffea pseudochromosomes,

685 pseudochromosome 2 is inferred to contain portions of at least five ancestral core eudicot

686 chromosomes. This suggests significant fractionation in this chromosome since the eudicot

687 triplication event (Denoeud et al., 2014). Even between Coffea and Asclepias,

688 pseudochromosome 2 maps to portions of several Asclepias linkage groups (Figs. 4, 5).

689 Therefore, the fractionation within this chromosome appears to have either occurred only within

690 the branch leading from the Gentianales ancestor to Coffea, or occurred earlier and then

691 continued along the branch leading to Asclepias. If the latter is true, then a higher frequency of

692 rearrangement may be a characteristic of this chromosome within the Gentianales, relative to

693 other chromosomes. Analyses of chromosomal rearrangements in Rhazya (Figure 1 in Sabir et al., 
694 2016) support this view, suggesting several rearrangements between the core eudicot triplication

695 event and the Gentianales ancestor, and continued rearrangement between that ancestor and

696 Rhazya. However, mapped genomic resources within other Asterids outside of Gentianales are

697 scarce, and are only found in taxa that have undergone additional genome duplication events

698 since the eudicot triplication (e.g., Solanum, Daucus; The Tomato Genome Consortium, 2012;

699 Iorizzo et al., 2016), complicating synteny assessments that might resolve the timing of

700 fractionation of this chromosome.

701 The production of physical maps of both Asclepias and Coffea chromosomes will help

702 resolve how frequently synteny has been disturbed between the two taxa. The ordered scaffold

703 maps presented here (Figs. S2-S7) contain only a few dozen markers, and trends apparent now

704 could be altered on maps with much greater resolution. The Coffea pseudochromosomes,

705 meanwhile, are still ultimately ordered by recombination frequency, and about half of the

706 scaffolds are placed with unknown orientation (Denoeud et al., 2014), which could manifest here

707 as apparent transpositions among adjacent markers.

708 Progesterone 5ß-reductase gene family

709 The name Asclepias comes from the Greek god of medicine, Asclepius, whose name was

710 applied to this genus for its potent secondary compounds. The cardenolides of Asclepias belong

711 to a class of steroidal compounds, cardiac glycosides, used to treat cardiac insufficiency. While

712 the genetic pathway that produces $\beta$-cardenolides (the form of cardenolide that includes the

713 medicinal compound digitoxin) is largely unknown, one of the early steps involves the

714 conversion of progesterone to 5 $\beta$-pregnane-3,20-dione (Gärtner, Wendroth \& Seitz, 1990;

715 Gärtner, Keilholz \& Seitz, 1994), catalyzed by the enzyme progesterone 5 $\beta$-reductase (P5 $\beta R$ ).

716 Orthologs of P5ßR occur broadly across seed plants, even in taxa that do not produce $\beta$ -

717 cardenolides, including Asclepias, which only produces $\alpha$-cardenolides (Bauer et al., 2010). The 
718 P5ßR1 locus has been characterized in Asclepias curassavica, but information about its genomic

719 context has remained unknown.

720 A coding P5 $3 \mathrm{R}$ ortholog was located in Asclepias syriaca on linkage group 11, sharing

$72198.4 \%$ amino acid identity with P5ßR from A. curassavica. This gene is supported by transcripts

722 from Asclepias, as well as mapped transcripts from Calotropis and proteins from Coffea. The

723 presence of a novel P5 $\beta \mathrm{R}$ pseudogene was also identified closely downstream from the expressed

724 gene (Table S2). Sharing high identity with the expressed P5 $\beta$, including several conserved

725 motifs, it clearly originated from a P5ßR duplication at some point. However, it is assumed to be

726 non-functional due to its degraded exons interrupted by multiple stop codons and lack of

727 expression evidence from the transcriptome.

728 A third region in Asclepias, on an unlinked scaffold, was matched by multiple P5 $\beta \mathrm{R}$

729 sequences from Catharanthus (Table S2). This region is made up of a single open reading frame

730 that shares only moderate identity with the Asclepias coding P5 $\beta \mathrm{R}$, and is not supported by

731 Asclepias transcript evidence. In a P5ßR phylogeny, the unlinked Asclepias region is sister to

732 Catharanthus P5ßR6 and a copy from Rhazya (Kellner et al., 2015; Sabir et al., 2016). These

733 sequences together are sister to all other P5ßR sequences analyzed except Picea, which was used

734 for rooting (Fig. 6).

735 While at least two P5 $3 \mathrm{R}$ paralogs have been identified in a wide range of plants, and

736 Rhazya, Rauvolfia, Catharanthus, and Tabernaemontana exhibit expression evidence of multiple

737 paralogs, Asclepias is reduced for this group of genes. Rauvolfia and Tabernaemontana are

738 known to produce cardenolides, but Catharanthus and Rhazya do not (Agrawal et al., 2012;

739 Sivagnanam \& Kumar, 2014; Abere et al., 2014; Hoopes et al., 2017). Calotropis is known to

740 produce $\beta$-cardenolides (Bauer et al., 2010; Pandey et al., 2016), and contains two P5 $\beta$ R paralogs

741 (Hoopes et al., 2017). It is possible that the fragmented nature of the current assembly precludes

742 identification of all existing P5 $\beta \mathrm{R}$ paralogs in A. syriaca, however, both genome assembly and 
743 transcript evidence point toward one functional P5 $\beta \mathrm{R}$ locus. While multiple genes are involved in

744 the production of $\beta$-cardenolides, it may be that the reduction in the P5 $\beta \mathrm{R}$ family is responsible

745 for the lack of these compounds in Asclepias, which only contains $\alpha$-cardenolides.

\section{CONCLUSIONS}

747 We present a draft genome assembly with linkage information of Asclepias syriaca,

748 assigning nearly half of scaffolds to linkage groups. While the assembly remains fragmented,

749 multiple lines of evidence indicate that nearly all of the gene space of Asclepias is represented

750 within the assembly.

751 Linkage information allowed assessment of synteny across the order Gentianales. Six of

752 eleven chromosomes retain similar gene content across the order, and these chromosomes have

753 likely remained stable since the divergence of eudicots. One chromosome has either experienced

754 dramatic fractionation since the divergence of Rubiaceae from other Gentianales, or experienced

755 earlier fractionation that continued within Gentianales.

756 Asclepias syriaca and its relatives are important systems for a wide range of evolutionary

757 and ecological studies, and are an important component of many ecosystems, serving as prolific

758 nectar producers and as hosts to a range of specially adapted species. The availability of the

759 Asclepias genome, coupled with genomic data from symbiotic organisms, particularly insects,

760 promises to inform important mechanisms of co-evolution (Agrawal \& Fishbein, 2008; Zhan et

761 al., 2011; Edger et al., 2015). We expect that the data presented here will advance these studies

762 and aid the discovery of novel insights into the origin and evolution of a charismatic family, the

763 production of important secondary compounds, and the ecological and evolutionary relationships

764 between milkweeds and their communities.

\section{ACKNOWLEDGMENTS}

766 The authors wish to kindly thank the following for important contributions to this work:

767 Winthrop Phippen for cultivating Asclepias, supplying tissue for sequencing, and harvesting 
768 fruits. Nicole Nasholm, Matt Parks, LaRinda Holland, Zoe Austin, and Lisa Garrison for DNA

769 extraction and library preparation. The Oregon State University Center for Genome Research and

770 Biocomputing for expert sequencing facilities and computational infrastructure. Access to the

771 TAIR database was provided under the Terms of Use, accessed on August 11, 2016, available at

772 http://www.arabidopsis.org/doc/about/tair terms of use/417.

773 Funding for this work is provided by the National Science Foundation Division of

774 Environmental Biology awards 0919389 (to M.F.) and 0919583 (to R.C.C. and A.L.) and

775 Integrative Organismal Systems award 1238731 (to C.D.B). The funders had no role in study

776 design, data collection and analysis, decision to publish, or preparation of the manuscript.

777 DATA AVAILABILITY

778 The whole genome shotgun project and transcriptome shotgun assembly have been

779 deposited at DDBJ/ENA/GenBank under the accessions MSXX01000000 and GFXT01000000,

780 respectively. Additional data, including the genome assembly and annotations, linkage group

781 information, target capture sequences, and gene family counts, have been deposited in the Oregon

782 State University institutional archive, ScholarsArchive@OSU (Weitemier, 2017; doi.org/10.7267/

783 N9M61HDR). A genome browser is available at www.milkweedgenome.org. 
784

785

786

787

788

789

790

791

792

793

794

795

796

797

798

799

800

801

802

803

804

805

806

807

808

809

810

811

\section{REFERENCES}

Abere TA, Ojogwu OK, Agoreyo FO, Eze GI. 2014. Antisickling and toxicological evaluation of the leaves of Rauwolfia vomitoria Afzel (Apocynaceae). Journal of Science and Practice of Pharmacy 1:11-15.

Agrawal AA. 2005. Natural selection on common milkweed (Asclepias syriaca) by a community of specialized insect herbivores. Evolutionary Ecology Research 7:651-667.

Agrawal AA, Fishbein M. 2006. Plant defense syndromes. Ecology 87:S132-S149.

Agrawal AA, Fishbein M. 2008. Phylogenetic escalation and decline of plant defense strategies. Proceedings of the National Academy of Sciences of the United States of America 105:10057-10060.

Agrawal AA, Petschenka G, Bingham RA, Weber MG, Rasmann S. 2012. Toxic cardenolides: chemical ecology and coevolution of specialized plant-herbivore interactions. New Phytologist 194:28-45. DOI: 10.1111/j.1469-8137.2011.04049.x.

Agrawal AA, Van Zandt PA. 2003. Ecological play in the coevolutionary theatre: genetic and environmental determinants of attack by a specialist weevil on milkweed. Journal of Ecology 91:1049-1059. DOI: 10.1046/j.1365-2745.2003.00831.x.

Altschul SF, Gish W, Miller W, Myers EW, Lipman DJ. 1990. Basic local alignment search tool. Journal of Molecular Biology 215:403-410. DOI: doi: 10.1016/S0022-2836(05)80360-2.

Amselem J, Cuomo CA, van Kan JAL, Viaud M, Benito EP, Couloux A, Coutinho PM, de Vries RP, Dyer PS, Fillinger S, Fournier E, Gout L, Hahn M, Kohn L, Lapalu N, Plummer KM, Pradier J-M, Quévillon E, Sharon A, Simon A, ten Have A, Tudzynski B, Tudzynski P, Wincker P, Andrew M, Anthouard V, Beever RE, Beffa R, Benoit I, Bouzid O, Brault B, Chen Z, Choquer M, Collémare J, Cotton P, Danchin EG, Da Silva C, Gautier A, Giraud C, Giraud T, Gonzalez C, Grossetete S, Güldener U, Henrissat B, Howlett BJ, Kodira C, Kretschmer M, Lappartient A, Leroch M, Levis C, Mauceli E, Neuvéglise C, Oeser B, Pearson M, Poulain J, Poussereau N, Quesneville H, Rascle C, Schumacher J, Ségurens B, Sexton A, Silva E, Sirven C, Soanes DM, Talbot NJ, Templeton M, Yandava C, Yarden O, Zeng Q, Rollins JA, Lebrun M-H, Dickman M. 2011. Genomic analysis of the 
812 necrotrophic fungal pathogens Sclerotinia sclerotiorum and Botrytis cinerea. PLoS Genetics 7:e1002230. DOI: 10.1371/journal.pgen.1002230.

814 Andrews S. 2010. FastQC - A Quality Control application for FastQ files.

815 Anisimova M, Gil M, Dufayard J-F, Dessimoz C, Gascuel O. 2011. Survey of branch support

816 methods demonstrates accuracy, power, and robustness of fast likelihood-based

817 approximation schemes. Systematic Biology 60:685-699. DOI: 10.1093/sysbio/syr041.

818 Bai C, Alverson WS, Follansbee A, Waller DM. 2012. New reports of nuclear DNA content for

819407 vascular plant taxa from the United States. Annals of Botany 110:1623-1629. DOI:

$820 \quad 10.1093 / a o b / m c s 222$.

821 Bainard JD, Bainard LD, Henry TA, Fazekas AJ, Newmaster SG. 2012. A multivariate analysis of 822 variation in genome size and endoreduplication in angiosperms reveals strong 823 phylogenetic signal and association with phenotypic traits. New Phytologist 196:1240824 1250. DOI: 10.1111/j.1469-8137.2012.04370.x.

825 Bao Z, Eddy SR. 2002. Automated de novo identification of repeat sequence families in 826 sequenced genomes. Genome Research 12:1269-1276. DOI: 10.1101/gr.88502.

827 Barnett D, Garrison E, Marth G, Stromberg M. 2013. bamtools.

828 Bauer P, Munkert J, Brydziun M, Burda E, Müller-Uri F, Gröger H, Muller YA, Kreis W. 2010. $829 \quad$ Highly conserved progesterone $5 \beta$-reductase genes (P5 $\beta$ R) from $5 \beta$-cardenolide-free and 830 53-cardenolide-producing angiosperms. Phytochemistry 71:1495-1505. DOI: $831 \quad$ 10.1016/j.phytochem.2010.06.004.

832 Benson G. 1999. Tandem repeats finder: a program to analyze DNA sequences. Nucleic Acids $833 \quad$ Research 27:573-580.

834 Bolger AM, Lohse M, Usadel B. 2014. Trimmomatic: a flexible trimmer for Illumina sequence 835 data. Bioinformatics 30:2114-2120. DOI: 10.1093/bioinformatics/btu170.

836 Brower LP, Brower J van, Corvino JM. 1967. Plant poisons in a terrestrial food chain.

837 Proceedings of the National Academy of Sciences of the United States of America 57:893838898. 
839 Brower LP, McEvoy PB, Williamson KL, Flannery MA. 1972. Variation in cardiac glycoside 840 content of Monarch butterflies from natural populations in eastern North America. $841 \quad$ Science 177:426. DOI: 10.1126/science.177.4047.426.

842 Broyles SB, Wyatt R. 1990. Paternity analysis in a natural population of Asclepias exaltata: 843 multiple paternity, functional gender, and the “pollen-donation hypothesis.” Evolution 44:1454-1468. DOI: 10.2307/2409329.

845 Bushnell B, Rood J. 2015. BBTools.

846 Chaplin SJ, Walker JL. 1982. Energetic constraints and adaptive significance of the floral display of a forest milkweed. Ecology 63:1857-1870. DOI: 10.2307/1940126.

848 Cruz F, Julca I, Gómez-Garrido J, Loska D, Marcet-Houben M, Cano E, Galán B, Frias L, Ribeca 849 P, Derdak S, Gut M, Sánchez-Fernández M, García JL, Gut IG, Vargas P, Alioto TS, 850

851 Gabaldón T. 2016. Genome sequence of the olive tree, Olea europaea. GigaScience 5:1-

852 Denoeud F, Carretero-Paulet L, Dereeper A, Droc G, Guyot R, Pietrella M, Zheng C, Alberti A, 853 12. DOI: 10.1186/s13742-016-0134-5.

857 Anthony F, Aprea G, Aury J-M, Bento P, Bernard M, Bocs S, Campa C, Cenci A, Combes M-C, Crouzillat D, Da Silva C, Daddiego L, De Bellis F, Dussert S, Garsmeur O, Gayraud T, Guignon V, Jahn K, Jamilloux V, Joët T, Labadie K, Lan T, Leclercq J, Lepelley M, Leroy T, Li L-T, Librado P, Lopez L, Muñoz A, Noel B, Pallavicini A, Perrotta G, Poncet V, Pot D, Priyono, Rigoreau M, Rouard M, Rozas J, TranchantGraziosi G, Henry RJ, Jayarama, Ming R, Nagai C, Rounsley S, Sankoff D, Giuliano G, Albert VA, Wincker P, Lashermes P. 2014. The coffee genome provides insight into the convergent evolution of caffeine biosynthesis. Science 345:1181-1184. DOI: 10.1126/science.1255274.

Denton JF, Lugo-Martinez J, Tucker AE, Schrider DR, Warren WC, Hahn MW. 2014. Extensive error in the number of genes inferred from draft genome assemblies. PLoS Computational Biology 10:e1003998. DOI: 10.1371/journal.pcbi.1003998. 
866 Edgar RC. 2004. MUSCLE: multiple sequence alignment with high accuracy and high throughput. Nucleic Acids Research 32:1792-1797. DOI: 10.1093/nar/gkh340.

868 Edger PP, Heidel-Fischer HM, Bekaert M, Rota J, Glöckner G, Platts AE, Heckel DG, Der JP, 869 Wafula EK, Tang M, Hofberger JA, Smithson A, Hall JC, Blanchette M, Bureau TE, Wright SI, dePamphilis CW, Schranz ME, Barker MS, Conant GC, Wahlberg N, Vogel H,

871

872 Pires JC, Wheat CW. 2015. The butterfly plant arms-race escalated by gene and genome duplications. Proceedings of the National Academy of Sciences of the United States of America 112:8362-8366. DOI: 10.1073/pnas.1503926112.

Elsworth B. 2012. Unearthing the genome of Lumbricus rubellus. Ph.D. dissertation Thesis.

876

877

878

879 880

881 882 883 884 885 886 887 888 889 890 891 892 893 Edinburgh, Scotland, U.K.: The University of Edinburgh.

Emms DM, Kelly S. 2015. OrthoFinder: solving fundamental biases in whole genome comparisons dramatically improves orthogroup inference accuracy. Genome Biology 16:1-14. DOI: 10.1186/s13059-015-0721-2.

Endress PK. 2006. Angiosperm floral evolution: morphological developmental framework. In: Advances in Botanical Research. Academic Press, 1-61.

Endress PK. 2015. Development and evolution of extreme synorganization in angiosperm flowers and diversity: a comparison of Apocynaceae and Orchidaceae. Annals of Botany:mcv119. DOI: $10.1093 / \mathrm{aob} / \mathrm{mcv} 119$.

Firrincieli A, Otillar R, Salamov A, Schmutz J, Khan Z, Redman RS, Fleck ND, Lindquist E, Grigoriev IV, Doty SL. 2015. Genome sequence of the plant growth promoting endophytic yeast Rhodotorula graminis WP1. Frontiers in Microbiology 6:978. DOI: 10.3389/fmicb.2015.00978.

Fishbein M, Chuba D, Ellison C, Mason-Gamer RJ, Lynch SP. 2011. Phylogenetic relationships of Asclepias (Apocynaceae) inferred from non-coding chloroplast DNA sequences. Systematic Botany 36:1008-1023. DOI: doi:10.1600/036364411X605010.

Fishbein M, Straub SCK, Boutte J, Hansen K, Cronn RC, Liston A. 2018. Evolution at the tips: Asclepias phylogenomics and new perspectives on leaf surfaces. American Journal of Botany 105:514-524. DOI: 10.1002/ajb2.1062. 
894 Fishbein M, Venable DL. 1996. Evolution of inflorescence design: Theory and data. Evolution 895 50:2165-2177.

896 Floudas D, Binder M, Riley R, Barry K, Blanchette RA, Henrissat B, Martínez AT, Otillar R, 897 Spatafora JW, Yadav JS, Aerts A, Benoit I, Boyd A, Carlson A, Copeland A, Coutinho 898 PM, de Vries RP, Ferreira P, Findley K, Foster B, Gaskell J, Glotzer D, Górecki P, 899 Heitman J, Hesse C, Hori C, Igarashi K, Jurgens JA, Kallen N, Kersten P, Kohler A, Kües

Gärtner DE, Keilholz W, Seitz HU. 1994. Purification, characterization and partial peptide

911 Gärtner DE, Wendroth S, Seitz HU. 1990. A stereospecific enzyme of the putative biosynthetic

912 pathway of cardenolides. FEBS Letters 271:239-242. DOI: 10.1016/0014-

913 5793(90)80415-F.

914 Goffeau A, Aert R, Agostini-Carbone ML, Ahmed A, Aigle M, Alberghina L, Albermann K,

915 Albers M, Aldea M, Alexandraki D, Aljinovic G, Allen E, Altmann R, Alt-Mörbe J, André 916 B, Andrews S, Ansorge W, Antoine G, Anwar R, Aparicio A, Araujo R, Arino J, Arnold W, 917 Arroyo J, Aviles E, Backes U, Baclet MC, Badcock K, Bahr A, Baladron V, Ballesta JPG, 918 Bankier AT, Banrevi A, Bargues M, Baron L, Barreiros T, Barrell BG, Barthe C, Barton 919 AB, Baur A, Bécam A-M, Becker A, Becker I, Beinhauer J, Benes V, Benit P, Berben G, 920 Bergantino E, Bergez P, Berno A, Bertani I, Biteau N, Bjourson AJ, Blöcker H, Blugeon 921 C, Bohn C, Boles E, Bolle PA, Bolotin-Fukuhara M, Bordonné R, Boskovic J, Bossier P, 

Buitrago MJ, Bussereau F, Bussey H, Camasses A, Carcano C, Carignani G, Carpenter J, Casamayor A, Casas C, Castagnoli L, Cederberg H, Cerdan E, Chalwatzis N, Chanet R, Chen E, Chéret G, Cherry JM, Chillingworth T, Christiansen C, Chuat J-C, Chung E, Düsterhöft A, Düsterhus S, Eki T, El Bakkoury M, Eide LG, Entian K-D, Eraso P, Cantalejo JM, García-Gonzalez MI, Garcia-Ramirez JJ, García-Saéz M, Gassenhuber H, Gatius M, Gattung S, Geisel C, Gent ME, Gentles S, Ghazvini M, Gigot D, Gilliquet V, Glansdorff N, Gómez-Peris A, Gonzaléz A, Goulding SE, Granotier C, Greco T, Grenson M, Grisanti P, Grivell LA, Grothues D, Gueldener U, Guerreiro P, Guzman E, Haasemann M, Habbig B, Hagiwara H, Hall J, Hallsworth K, Hamberg K, Hamlin N, Hand NJ, Hanemann V, Hani J, Hankeln T, Hansen M, Harris D, Harris DE, Hartzell G, Hatat D, Hattenhorst U, Hawkins J, Hebling U, Hegemann J, Hein C, Hennemann A, Hennessy K, Herbert CJ, Hernandez K, Hernando Y, Herrero E, Heumann K, Heuss-Neitzel D, Hewitt 
M-E, Hughes B, Hunicke-Smith S, Hunt S, Hunt SE, Huse K, Hyman RW, Iborra F, Indge KJ, Iraqui Houssaini I, Isono K, Jacq C, Jacquet M, Jacquier A, Jagels K, Jäger W, James CM, Jauniaux JC, Jia Y, Jier M, Jimenez A, Johnson D, Johnston L, Johnston M, Jones L, Jones M, Jonniaux J-L, Kaback DB, Kallesøe T, Kalman S, Kalogeropoulos A, Karpfinger-Hartl L, Kashkari D, Katsoulou C, Kayser A, Kelly A, Keng T, Keuchel H, Kiesau P, Kirchrath L, Kirsten J, Kleine K, Kleinhans U, Klima R, Komp C, Kordes E, Korol S, Kötter P, Krämer C, Kramer B, Kramer W, Kreisl P, Kucaba T, Kuester H, Kurdi C, Li ZY, Liebl S, Lin A, Lin D, Logghe M, Lohan AJE, Louis EJ, Lucchini G, Lutzenkirchen K, Lyck R, Lye G, Maarse AC, Maat MJ, Macri C, Madania A, Maftahi M, Maia e Silva A, Maillier E, Mallet L, Mannhaupt G, Manus V, Marathe R, Marck C, Marconi A, Mardis E, Martegani E, Martin R, Mathieu A, Maurer KTC, Mazón MJ, Mazzoni C, McConnell D, McDonald S, McKee RA, McReynolds ADK, Melchioretto P, Menezes S, Messenguy F, Mewes HW, Michaux G, Miller N, Minenkova O, Miosga T, Mirtipati S, Möller-Rieker S, Möstl D, Molemans F, Monnet A, Monnier A-L, Montague MA, Moro M, Mosedale D, Möstl D, Moule S, Mouser L, Murakami Y, Müller-Auer S, Mulligan J, Murphy L, Muzi Falconi M, Naitou M, Nakahara K, Namath A, Nasr F, Navas L, Nawrocki A, Nelson J, Nentwich U, Netter P, Neu R, Newlon CS, Nhan M, Niblett D, Nicaud J-M, Niedenthal RK, Nombela C, Noone D, Norgren R, Nußbaumer B, Obermaier B, Odell C, Öfner P, Oh C, Oliver K, Oliver SG, Ouellette BF, Ozawa M, Paces V, Pallier C, Pandolfo D, Panzeri L, Paoluzi S, Parle-McDermott AG, Pascolo S, Paricio N, Pauley A, Paulin L, Pearson BM, Pearson D, Peluso D, Perea J, Pérez-Alonso M, Pérez-Ortin JE, Perrin A, Petel FX, Pettersson B, Pfeiffer F, Philippsen P, Piérard A, Piravandi E, Planta RJ, Plevani P, Poch O, Poetsch B, Pohl FM, Pohl TM, Pöhlmann R, Poirey R, Portetelle D, Portillo F, Potier S, Proft M, Prydz H, Pujol A, Purnelle B, Puzos V, Rajandream MA, Ramezani Rad M, Rasmussen SW, Raynal A, Rebischung C, Rechmann S, Remacha M, Revuelta JL, Rice P, Richard G-F, Richards C, Richterich P, 
978

979

980

981

982

983

984

985

986

987

988

989

990

991

992

993

994

995

996

997

998

999

1000

1001

1002

1003

1004

1005

Rieger M, Rifkin L, Riles L, Rinaldi T, Rinke M, Robben J, Roberts AB, Roberts D, Rodriguez F, Rodriguez-Belmonte E, Rodrigues-Pousada C, Rodriguez-Torres AM, Rose M, Rossau R, Rowley N, Rupp T, Ruzzi M, Saeger W, Saiz JE, Saliola M, Salom D, Saluz HP, Sánchez-Perez M, Santos MA, Sanz E, Sanz JE, Saren A-M, Sartorello F, Sasanuma M, Sasanuma S-I, Scarcez T, Schaaf-Gerstenschläger I, Schäfer B, Schäfer M, Scharfe M, Scherens B, Schroff N, Sen-Gupta M, Shibata T, Schmidheini T, Schmidt ER, Schneider C, Scholler P, Schramm S, Schreer A, Schröder M, Schwager C, Schwarz S, Schwarzlose C, Schweitzer B, Schweizer M, Sdicu A-M, Sehl P, Sensen C, Sgouros JG, Shogren T, Shore L, Su Y, Skala J, Skelton J, Slonimski PP, Smits PHM, Smith V, Soares H, Soeda E, Soler-Mira A, Sor F, Soriano N, Souciet JL, Soustelle C, Spiegelberg R, Stateva LI, Steensma HY, Stegemann J, Steiner S, Stellyes L, Sterky F, Storms RK, Peter HSt, Stucka R, Taich A, Talla E, Tarassov I, Tashiro H, Taylor P, Teodoru C, Tettelin H, Thierry A, Thireos G, Tobiasch E, Tovan D, Trevaskis E, Tsuchiya Y, Tzermia M, Uhlen M, Underwood A, Unseld M, Urbanus JHM, Urrestarazu A, Ushinsky S, Valens M, Valle G, Van Broekhoven A, Vandenbol M, Van der Aart QJM, Van Der Linden CG, Van Dyck L, Vanoni M, van Vliet-Reedijk JC, Vassarotti A, Vaudin M, Vaughan K, Verhasselt P, Vetter I, Vierendeels F, Vignati D, Vilela C, Vissers S, Vleck C, Vo DT, Vo DH, Voet M, Volckaert G, Von Wettstein D, Voss H, Vreken P, Wach A, Wagner G, Walsh SV, Wambutt R, Wang H, Wang Y, Warmington JR, Waterston R, Watson MD, Weber N, Wedler E, Wedler H, Wei Y, Whitehead S, Wicksteed BL, Wiemann S, Wilcox L, Wilson C, Wilson R, Winant A, Winnett E, Winsor B, Wipfli P, Wölfl S, Wohldman P, Wolf K, Wolfe KH, Wright LF, Wurst H, Xu G, Yamazaki M, Yelton MA, Yokohama K, Yoshikawa A, Yuping S, Zaccaria P, Zagulski M, Zimmermann FK, Zimmermann J, Zimmermann M, Zhong WW, Zollner A, Zumstein E. 1997. The yeast genome directory. Nature 387:5-5.

Góngora-Castillo E, Childs KL, Fedewa G, Hamilton JP, Liscombe DK, Magallanes-Lundback M, Mandadi KK, Nims E, Runguphan W, Vaillancourt B, Varbanova-Herde M, DellaPenna D, McKnight TD, O’Connor S, Buell CR. 2012a. Development of transcriptomic resources for interrogating the biosynthesis of monoterpene indole

Peer] reviewing PDF | (2019:04:36833:2:0:NEW 5 Aug 2019) 
1006

1007

1008

1009

1010

1011

1012

1013

1014

1015

1016

1017

1018

1019

1020

1021

1022

1023

1024

1025

1026

1027

1028

1029

1030

1031

1032

alkaloids in medicinal plant species. PLoS ONE 7:e52506. DOI: 10.1371/journal.pone.0052506.

Góngora-Castillo E, Fedewa G, Yeo Y, Chappell J, DellaPenna D, Buell CR. 2012b. Genomic approaches for interrogating the biochemistry of medicinal plant species. In: David A. Hopwood ed. Methods in Enzymology. Academic Press, 139-159.

Grabherr MG, Haas BJ, Yassour M, Levin JZ, Thompson DA, Amit I, Adiconis X, Fan L, Raychowdhury R, Zeng Q, Chen Z, Mauceli E, Hacohen N, Gnirke A, Rhind N, di Palma F, Birren BW, Nusbaum C, Lindblad-Toh K, Friedman N, Regev A. 2011. Full-length transcriptome assembly from RNA-Seq data without a reference genome. Nature Biotechnology 29:644-652. DOI: 10.1038/nbt.1883.

Guindon S, Dufayard J-F, Lefort V, Anisimova M, Hordijk W, Gascuel O. 2010. New algorithms and methods to estimate maximum-likelihood phylogenies: assessing the performance of PhyML 3.0. Systematic Biology 59:307-321. DOI: 10.1093/sysbio/syq010.

Guindon S, Gascuel O. 2003. A simple, fast, and accurate algorithm to estimate large phylogenies by maximum likelihood. Systematic Biology 52:696-704. DOI: 10.1080/10635150390235520.

Haas BJ, Delcher AL, Mount SM, Wortman JR, Smith Jr RK, Hannick LI, Maiti R, Ronning CM, Rusch DB, Town CD, Salzberg SL, White O. 2003. Improving the Arabidopsis genome annotation using maximal transcript alignment assemblies. Nucleic Acids Research 31:5654-5666. DOI: 10.1093/nar/gkg770.

Haas BJ, Papanicolaou A, Yassour M, Grabherr M, Blood PD, Bowden J, Couger MB, Eccles D, Li B, Lieber M, MacManes MD, Ott M, Orvis J, Pochet N, Strozzi F, Weeks N, Westerman R, William T, Dewey CN, Henschel R, LeDuc RD, Friedman N, Regev A. 2013. De novo transcript sequence reconstruction from RNA-seq using the Trinity platform for reference generation and analysis. Nature Protocols 8:1494-1512.

Haas BJ, Salzberg SL, Zhu W, Pertea M, Allen JE, Orvis J, White O, Buell CR, Wortman JR. 2008. Automated eukaryotic gene structure annotation using EVidenceModeler and the 
1033

1034

1035

1036

1037

1038

1039

1040

1041

1042

1043

1044

1045

1046

1047

1048

1049

1050

1051

1052

1053

1054

1055

1056

1057

1058

1059

Program to Assemble Spliced Alignments. Genome Biology 9:1-22. DOI: 10.1186/gb2008-9-1-r7.

Hoopes GM, Hamilton JP, Kim J, Zhao D, Wiegert-Rininger K, Crisovan E, Buell CR. 2017. Genome Assembly and Annotation of the Medicinal Plant <em>Calotropis gigantea</em>, a Producer of Anti-Cancer and Anti-Malarial Cardenolides. G3: Genes| Genomes|Genetics. DOI: 10.1534/g3.117.300331.

Hu J, Chen C, Peever T, Dang H, Lawrence C, Mitchell T. 2012. Genomic characterization of the conditionally dispensable chromosome in Alternaria arborescens provides evidence for horizontal gene transfer. BMC Genomics 13:171. DOI: 10.1186/1471-2164-13-171.

Huang X, Madan A. 1999. CAP3: A DNA sequence assembly program. Genome Research 9:868877. DOI: $10.1101 /$ gr.9.9.868.

Humann J, Ficklin SP, Lee T, Cheng C-H, Jung S, Wegrzyn J, Neale D, Main D. 2016. GenSAS v4.0: A web-based platform for structural and functional genome annotation and curation. In: Plant and Animal Genome XXIV. San Diego, California,.

Iorizzo M, Ellison S, Senalik D, Zeng P, Satapoomin P, Huang J, Bowman M, Iovene M, Sanseverino W, Cavagnaro P, Yildiz M, Macko-Podgórni A, Moranska E, Grzebelus E, Grzebelus D, Ashrafi H, Zheng Z, Cheng S, Spooner D, Van Deynze A, Simon P. 2016. A high-quality carrot genome assembly provides new insights into carotenoid accumulation and asterid genome evolution. Nature Genetics 48:657.

Jiang N. 2015.Repeat Library Construction-Basic. Available at http://weatherby.genetics.utah.edu/MAKER/wiki/index.php/Repeat_Library_Construction -Basic (accessed October 7, 2015).

Jiao Y, Paterson AH. 2014. Polyploidy-associated genome modifications during land plant evolution. Philosophical Transactions of the Royal Society B: Biological Sciences 369:20130355. DOI: 10.1098/rstb.2013.0355.

Jones P, Binns D, Chang H-Y, Fraser M, Li W, McAnulla C, McWilliam H, Maslen J, Mitchell A, Nuka G, Pesseat S, Quinn AF, Sangrador-Vegas A, Scheremetjew M, Yong S-Y, Lopez R, 
1060

1061

1062

1063

1064

1065

1066

1067

1068

1069

1070

1071

1072

1073

1074

1075

1076

1077

1078

1079

1080

1081

1082

1083

1084

1085

1086

Hunter S. 2014. InterProScan 5: genome-scale protein function classification. Bioinformatics 30:1236-1240. DOI: 10.1093/bioinformatics/btu031.

Kajitani R, Toshimoto K, Noguchi H, Toyoda A, Ogura Y, Okuno M, Yabana M, Harada M, Nagayasu E, Maruyama H, Kohara Y, Fujiyama A, Hayashi T, Itoh T. 2014. Efficient de novo assembly of highly heterozygous genomes from whole-genome shotgun short reads. Genome Research 24:1384-1395. DOI: 10.1101/gr.170720.113.

Kearse M, Moir R, Wilson A, Stones-Havas S, Cheung M, Sturrock S, Buxton S, Cooper A, Markowitz S, Duran C, Thierer T, Ashton B, Meintjes P, Drummond A. 2012. Geneious Basic: an integrated and extendable desktop software platform for the organization and analysis of sequence data. Bioinformatics 28:1647-1649. DOI: 10.1093/bioinformatics/bts199.

Kellner F, Kim J, Clavijo BJ, Hamilton JP, Childs KL, Vaillancourt B, Cepela J, Habermann M, Steuernagel B, Clissold L, McLay K, Buell CR, O’Connor SE. 2015. Genome-guided investigation of plant natural product biosynthesis. The Plant Journal 82:680-692. DOI: 10.1111/tpj.12827.

Kennedy RC, Unger MF, Christley S, Collins FH, Madey GR. 2010.TESeeker. Available at https://www3.nd.edu/ teseeker/download.html (accessed September 30, 2015).

Kennedy RC, Unger MF, Christley S, Collins FH, Madey GR. 2011. An automated homologybased approach for identifying transposable elements. BMC Bioinformatics 12:1-10. DOI: 10.1186/1471-2105-12-130.

Kent WJ. 2002. BLAT—The BLAST-Like Alignment Tool. Genome Research 12:656-664. DOI: 10.1101/gr.229202.

Kluge AG, Farris JS. 1969. Quantitative phyletics and the evolution of Anurans. Systematic Biology 18:1-32. DOI: 10.1093/sysbio/18.1.1.

Kohany O, Gentles AJ, Hankus L, Jurka J. 2006. Annotation, submission and screening of repetitive elements in Repbase: RepbaseSubmitter and Censor. BMC Bioinformatics 7:17. DOI: $10.1186 / 1471-2105-7-474$. 
1087 Korf I. 2004. Gene finding in novel genomes. BMC Bioinformatics 5:1-9. DOI: 10.1186/1471$1088 \quad$ 2105-5-59.

1089 Kwon CW, Park K-M, Kang B-C, Kweon D-H, Kim M-D, Shin SW, Je YH, Chang P-S. 2015. 1090 Cysteine protease profiles of the medicinal plant Calotropis procera R. Br. revealed by de 1091 novo transcriptome analysis. PLoS ONE 10:e0119328. DOI:

$1092 \quad$ 10.1371/journal.pone.0119328.

1093 La Rosa RJ, Conner JK. 2017. Floral function: effects of traits on pollinators, male and female 1094 pollination success, and female fitness across three species of milkweeds (Asclepias). 1095 American Journal of Botany 104:150-160. DOI: 10.3732/ajb.1600328.

1096 Labeyrie E, Dobler S. 2004. Molecular adaptation of Chrysochus leaf beetles to toxic compounds 1097 in their food plants. Molecular Biology and Evolution 21:218-221. DOI: 10.1093/molbev/ $1098 \quad$ msg240.

1099 Langmead B, Salzberg SL. 2012. Fast gapped-read alignment with Bowtie 2. Nature Methods 1100 9:357-359. DOI: 10.1038/nmeth.1923.

1101 Lee T, Peace C, Jung S, Zheng P, Main D, Cho I. 2011. GenSAS — An online integrated genome 1102 sequence annotation pipeline. 2011 4th International Conference on Biomedical 1103 Engineering and Informatics (BMEI) 4:1967-1973. DOI: 10.1109/BMEI.2011.6098712.

1104 Li H, Durbin R. 2010. Fast and accurate long-read alignment with Burrows-Wheeler transform. 1105 Bioinformatics 26:589-595. DOI: 10.1093/bioinformatics/btp698.

1106 Li W, Godzik A. 2006. Cd-hit: a fast program for clustering and comparing large sets of protein 1107 or nucleotide sequences. Bioinformatics 22:1658-1659. DOI:

$1108 \quad$ 10.1093/bioinformatics/btl158.

1109 Li H, Handsaker B, Wysoker A, Fennell T, Ruan J, Homer N, Marth G, Abecasis G, Durbin R, 11101000 Genome Project Data Processing Subgroup. 2009. The Sequence Alignment/Map 1111 format and SAMtools. Bioinformatics 25:2078-2079. DOI:

1112 10.1093/bioinformatics/btp352. 
1113 Li B, Zong Y, Du Z, Chen Y, Zhang Z, Qin G, Zhao W, Tian S. 2015. Genomic characterization

1114 reveals insights into patulin biosynthesis and pathogenicity in Penicillium species.

1115 Molecular Plant-Microbe Interactions 28:635-647. DOI: 10.1094/MPMI-12-14-0398-FI.

1116 Librado P, Vieira FG, Rozas J. 2012. BadiRate: estimating family turnover rates by likelihood-

1117 based methods. Bioinformatics 28:279-281. DOI: 10.1093/bioinformatics/btr623.

1118 Liu B, Shi Y, Yuan J, Hu X, Zhang H, Li N, Li Z, Chen Y, Mu D, Fan W. 2013. Estimation of

1119 genomic characteristics by analyzing k-mer frequency in de novo genome projects.

$1120 \quad$ arXiv:1308.2012v1 [q-bio].

1121 Livshultz T, Kaltenegger E, Straub SCK, Weitemier K, Hirsch E, Koval K, Mema L, Liston A.

1122 2018. Evolution of pyrrolizidine alkaloid biosynthesis in Apocynaceae: revisiting the

1123 defence de-escalation hypothesis. New Phytologist 218:762-773. DOI:

1124 10.1111/nph.15061.

1125 Lohse M, Nagel A, Herter T, May P, Schroda M, Zrenner R, Tohge T, Fernie AR, Stitt M, Usadel

1126 B. 2014. Mercator: a fast and simple web server for genome scale functional annotation of 1127 plant sequence data. Plant, Cell \& Environment 37:1250-1258. DOI: 10.1111/pce.12231.

1128 Lowe TM, Eddy SR. 1997. tRNAscan-SE: A program for improved detection of transfer RNA

1129 genes in genomic sequence. Nucleic Acids Research 25:955-964. DOI:

$1130 \quad 10.1093 / \mathrm{nar} / 25.5 .0955$.

1131 Ma L-J, van der Does HC, Borkovich KA, Coleman JJ, Daboussi M-J, Di Pietro A, Dufresne M, 1132 Freitag M, Grabherr M, Henrissat B, Houterman PM, Kang S, Shim W-B, Woloshuk C, 1133 Xie X, Xu J-R, Antoniw J, Baker SE, Bluhm BH, Breakspear A, Brown DW, Butchko 1134 RAE, Chapman S, Coulson R, Coutinho PM, Danchin EGJ, Diener A, Gale LR, Gardiner 1135 DM, Goff S, Hammond-Kosack KE, Hilburn K, Hua-Van A, Jonkers W, Kazan K, Kodira 1136 CD, Koehrsen M, Kumar L, Lee Y-H, Li L, Manners JM, Miranda-Saavedra D, 1137 Mukherjee M, Park G, Park J, Park S-Y, Proctor RH, Regev A, Ruiz-Roldan MC, Sain D, 1138 Sakthikumar S, Sykes S, Schwartz DC, Turgeon BG, Wapinski I, Yoder O, Young S, Zeng 1139 Q, Zhou S, Galagan J, Cuomo CA, Kistler HC, Rep M. 2010. Comparative genomics 
1140

1141

1142

1143

1144

1145

1146

1147

1148

1149

1150

1151

1152

1153

1154

1155

1156

1157

1158

1159

1160

1161

1162

1163

1164

1165

1166

1167

reveals mobile pathogenicity chromosomes in Fusarium. Nature 464:367-373. DOI: 10.1038/nature08850.

Magoč T, Salzberg SL. 2011. FLASH: fast length adjustment of short reads to improve genome assemblies. Bioinformatics 27:2957-2963. DOI: 10.1093/bioinformatics/btr507.

Margarido GRA, Souza AP, Garcia AAF. 2007. OneMap: software for genetic mapping in outcrossing species. Hereditas 144:78-79. DOI: 10.1111/j.2007.0018-0661.02000.x.

Martinez D, Berka RM, Henrissat B, Saloheimo M, Arvas M, Baker SE, Chapman J, Chertkov O, Coutinho PM, Cullen D, Danchin EGJ, Grigoriev IV, Harris P, Jackson M, Kubicek CP, Han CS, Ho I, Larrondo LF, de Leon AL, Magnuson JK, Merino S, Misra M, Nelson B, Putnam N, Robbertse B, Salamov AA, Schmoll M, Terry A, Thayer N, WesterholmParvinen A, Schoch CL, Yao J, Barabote R, Barbote R, Nelson MA, Detter C, Bruce D, Kuske CR, Xie G, Richardson P, Rokhsar DS, Lucas SM, Rubin EM, Dunn-Coleman N, Ward M, Brettin TS. 2008. Genome sequencing and analysis of the biomass-degrading fungus Trichoderma reesei (syn. Hypocrea jecorina). Nature Biotechnology 26:553-560. DOI: $10.1038 /$ nbt1403.

Medicinal Plant Consortium. 2011.Release of the medicinal plant consortium transcriptome resources. Available at http://medicinalplantgenomics.msu.edu/final_version_release_info.shtml (accessed August 18, 2016).

Mitchell A, Chang H-Y, Daugherty L, Fraser M, Hunter S, Lopez R, McAnulla C, McMenamin C, Nuka G, Pesseat S, Sangrador-Vegas A, Scheremetjew M, Rato C, Yong S-Y, Bateman A, Punta M, Attwood TK, Sigrist CJA, Redaschi N, Rivoire C, Xenarios I, Kahn D, Guyot D, Bork P, Letunic I, Gough J, Oates M, Haft D, Huang H, Natale DA, Wu CH, Orengo C, Sillitoe I, Mi H, Thomas PD, Finn RD. 2015. The InterPro protein families database: the classification resource after 15 years. Nucleic Acids Research 43:D213-D221. DOI: 10.1093/nar/gku1243.

Morgan MT, Schoen DJ. 1997. Selection on reproductive characters: floral morphology in Asclepias syriaca. Heredity 79:433.

Peer) reviewing PDF | (2019:04:36833:2:0:NEW 5 Aug 2019) 
1168 Munkert J, Pollier J, Miettinen K, Van Moerkercke A, Payne R, Müller-Uri F, Burlat V, O’Connor

1169 SE, Memelink J, Kreis W, Goossens A. 2015. Iridoid synthase activity is common among

1170 the plant progesterone 5 3 -reductase family. Molecular Plant 8:136-152. DOI:

$1171 \quad$ 10.1016/j.molp.2014.11.005.

1172 Ng KP, Yew SM, Chan CL, Soo-Hoo TS, Na SL, Hassan H, Ngeow YF, Hoh C-C, Lee K-W, Yee

1173 W-Y. 2012. Sequencing of Cladosporium sphaerospermum, a Dematiaceous fungus

1174 isolated from blood culture. Eukaryotic Cell 11:705-706. DOI: 10.1128/EC.00081-12.

1175 Nierman WC, Pain A, Anderson MJ, Wortman JR, Kim HS, Arroyo J, Berriman M, Abe K,

1176 Archer DB, Bermejo C, Bennett J, Bowyer P, Chen D, Collins M, Coulsen R, Davies R,

1177 Dyer PS, Farman M, Fedorova N, Fedorova N, Feldblyum TV, Fischer R, Fosker N,

1178 Fraser A, García JL, García MJ, Goble A, Goldman GH, Gomi K, Griffith-Jones S,

1179 Gwilliam R, Haas B, Haas H, Harris D, Horiuchi H, Huang J, Humphray S, Jiménez J,

1180 Keller N, Khouri H, Kitamoto K, Kobayashi T, Konzack S, Kulkarni R, Kumagai T,

1181 Lafon A, Lafton A, Latgé J-P, Li W, Lord A, Lu C, Majoros WH, May GS, Miller BL,

1182 Mohamoud Y, Molina M, Monod M, Mouyna I, Mulligan S, Murphy L, O’Neil S, Paulsen

1183 I, Peñalva MA, Pertea M, Price C, Pritchard BL, Quail MA, Rabbinowitsch E, Rawlins N,

1184 Rajandream M-A, Reichard U, Renauld H, Robson GD, Rodriguez de Córdoba S,

1185 Rodríguez-Peña JM, Ronning CM, Rutter S, Salzberg SL, Sanchez M, Sánchez-Ferrero

1186 JC, Saunders D, Seeger K, Squares R, Squares S, Takeuchi M, Tekaia F, Turner G,

1187 Vazquez de Aldana CR, Weidman J, White O, Woodward J, Yu J-H, Fraser C, Galagan JE,

1188 Asai K, Machida M, Hall N, Barrell B, Denning DW. 2005. Genomic sequence of the

1189 pathogenic and allergenic filamentous fungus Aspergillus fumigatus. Nature 438:1151-

1190 1156. DOI: 10.1038/nature04332.

1191 Ohm RA, Feau N, Henrissat B, Schoch CL, Horwitz BA, Barry KW, Condon BJ, Copeland AC,

1192 Dhillon B, Glaser F, Hesse CN, Kosti I, LaButti K, Lindquist EA, Lucas S, Salamov AA,

1193 Bradshaw RE, Ciuffetti L, Hamelin RC, Kema GHJ, Lawrence C, Scott JA, Spatafora JW,

1194 Turgeon BG, de Wit PJGM, Zhong S, Goodwin SB, Grigoriev IV. 2012. Diverse lifestyles 
1195

1196

1197

1198

1199

1200

1201

1202

1203

1204

1205

1206

1207

1208

1209

1210

1211

1212

1213

1214

1215

1216

1217

1218

1219

1220

1221

1222

and strategies of plant pathogenesis encoded in the genomes of eighteen Dothideomycetes fungi. PLoS pathogens 8:e1003037. DOI: 10.1371/journal.ppat.1003037.

Pandey A, Swarnkar V, Pandey T, Srivastava P, Kanojiya S, Mishra DK, Tripathi V. 2016. Transcriptome and Metabolite analysis reveal candidate genes of the cardiac glycoside biosynthetic pathway from Calotropis procera. Scientific Reports 6:34464.

Park S, Ruhlman TA, Sabir JS, Mutwakil MH, Baeshen MN, Sabir MJ, Baeshen NA, Jansen RK. 2014. Complete sequences of organelle genomes from the medicinal plant Rhazya stricta (Apocynaceae) and contrasting patterns of mitochondrial genome evolution across asterids. BMC Genomics 15:405. DOI: 10.1186/1471-2164-15-405.

Parkhomchuk D, Borodina T, Amstislavskiy V, Banaru M, Hallen L, Krobitsch S, Lehrach H, Soldatov A. 2009. Transcriptome analysis by strand-specific sequencing of complementary DNA. Nucleic Acids Research 37:e123-e123. DOI: 10.1093/nar/gkp596.

Pérez-Bermúdez P, Moya García AA, Tuñón I, Gavidia I. 2010. Digitalis purpurea P5ßR2, encoding steroid 5 $\beta$-reductase, is a novel defense-related gene involved in cardenolide biosynthesis. New Phytologist 185:687-700. DOI: 10.1111/j.1469-8137.2009.03080.x.

Price AL, Jones NC, Pevzner PA. 2005. De novo identification of repeat families in large genomes. Bioinformatics 21:i351-i358. DOI: 10.1093/bioinformatics/bti1018.

Proost S, Bel MV, Sterck L, Billiau K, Parys TV, Peer YV de, Vandepoele K. 2009. PLAZA: A Comparative Genomics Resource to Study Gene and Genome Evolution in Plants. The Plant Cell Online 21:3718-3731. DOI: 10.1105/tpc.109.071506.

Proost S, Van Bel M, Vaneechoutte D, Van de Peer Y, Inzé D, Mueller-Roeber B, Vandepoele K. 2015. PLAZA 3.0: an access point for plant comparative genomics. Nucleic Acids Research 43:D974-D981. DOI: 10.1093/nar/gku986.

Pruitt K, Brown G, Tatusova T, Maglott D. 2002. The Reference Sequence (RefSeq) Database. In: McEntyre J, Ostell J eds. The NCBI Handbook. Bethesda, MD: National Center for Biotechnology Information, Chapter 18.

R Core Team. 2014. R: A language and environment for statistical computing. Vienna, Austria: R Foundation for Statistical Computing.

Peer] reviewing PDF | (2019:04:36833:2:0:NEW 5 Aug 2019) 
1223 Rahman AYA, Usharraj AO, Misra BB, Thottathil GP, Jayasekaran K, Feng Y, Hou S, Ong SY,

1224 Ng FL, Lee LS, Tan HS, Sakaff MKLM, Teh BS, Khoo BF, Badai SS, Aziz NA, Yuryev

1225 A, Knudsen B, Dionne-Laporte A, Mchunu NP, Yu Q, Langston BJ, Freitas TAK, Young

1226 AG, Chen R, Wang L, Najimudin N, Saito JA, Alam M. 2013. Draft genome sequence of

1227 the rubber tree Hevea brasiliensis. BMC Genomics 14:75. DOI: 10.1186/1471-2164-14-

$1228 \quad 75$.

1229 Rasmann S, Agrawal AA, Cook SC, Erwin AC. 2009. Cardenolides, induced responses, and

1230 interactions between above- and belowground herbivores of milkweed (Asclepias spp.).

$1231 \quad$ Ecology 90:2393-2404.

1232 Rasmann S, Erwin AC, Halitschke R, Agrawal AA. 2011. Direct and indirect root defences of

1233 milkweed (Asclepias syriaca): trophic cascades, trade-offs and novel methods for

1234 studying subterranean herbivory. Journal of Ecology 99:16-25. DOI: 10.1111/j.1365-

$1235 \quad$ 2745.2010.01713.x.

1236 Rice P, Longden I, Bleasby A. 2000. EMBOSS: The European Molecular Biology Open Software

1237 Suite. Trends in Genetics 16:276-277. DOI: 10.1016/S0168-9525(00)02024-2.

1238 Riley R, Salamov AA, Brown DW, Nagy LG, Floudas D, Held BW, Levasseur A, Lombard V,

1239 Morin E, Otillar R, Lindquist EA, Sun H, LaButti KM, Schmutz J, Jabbour D, Luo H,

1240 Baker SE, Pisabarro AG, Walton JD, Blanchette RA, Henrissat B, Martin F, Cullen D,

1241 Hibbett DS, Grigoriev IV. 2014. Extensive sampling of basidiomycete genomes

1242 demonstrates inadequacy of the white-rot/brown-rot paradigm for wood decay fungi.

1243 Proceedings of the National Academy of Sciences of the United States of America

1244 111:9923-9928. DOI: 10.1073/pnas.1400592111.

1245 Sabir JSM, Jansen RK, Arasappan D, Calderon V, Noutahi E, Zheng C, Park S, Sabir MJ,

1246 Baeshen MN, Hajrah NH, Khiyami MA, Baeshen NA, Obaid AY, Al-Malki AL, Sankoff

1247 D, El-Mabrouk N, Ruhlman TA. 2016. The nuclear genome of Rhazya stricta and the

1248 evolution of alkaloid diversity in a medically relevant clade of Apocynaceae. Scientific

$1249 \quad$ Reports 6:33782. 
1250 Schmieder R, Edwards R. 2011. Fast identification and removal of sequence contamination from

1251 genomic and metagenomic datasets. PLOS ONE 6:e17288. DOI:

$1252 \quad$ 10.1371/journal.pone.0017288.

1253 Shaw JJ, Berbasova T, Sasaki T, Jefferson-George K, Spakowicz DJ, Dunican BF, Portero CE, 1254 Narváez-Trujillo A, Strobel SA. 2015. Identification of a fungal 1,8-cineole synthase from

1255 Hypoxylon sp. with specificity determinants in common with the plant synthases. The 1256 Journal of Biological Chemistry 290:8511-8526. DOI: 10.1074/jbc.M114.636159.

1257 Simão FA, Waterhouse RM, Ioannidis P, Kriventseva EV, Zdobnov EM. 2015. BUSCO: assessing 1258 genome assembly and annotation completeness with single-copy orthologs.

1259 Bioinformatics 31:3210-3212. DOI: 10.1093/bioinformatics/btv351.

1260 Sivagnanam S, Kumar A. 2014. Preliminary phytochemical analysis of Tabernaemontana 1261 alternifolia. International Journal of Pharma and Bio Sciences 5:(B) 283-287.

1262 Smit AFA, Hubley R, Green P. 2015.RepeatMasker. Available at http://www.repeatmasker.org/ 1263 (accessed October 7, 2015).

1264 Solexa, Inc. 2006. Protocol for whole genome sequencing using Solexa technology.

1265 BioTechniques Protocol Guide 2007:291.

1266 Sparrow FK, Pearson NL. 1948. Pollen compatibility in Asclepias syriaca. Journal of $1267 \quad$ Agricultural Research 77:187-199.

1268 Stanke M, Diekhans M, Baertsch R, Haussler D. 2008. Using native and syntenically mapped 1269 cDNA alignments to improve de novo gene finding. Bioinformatics 24:637-644. DOI: $1270 \quad$ 10.1093/bioinformatics/btn013.

1271 Straub SCK, Cronn RC, Edwards C, Fishbein M, Liston A. 2013. Horizontal transfer of DNA 1272 from the mitochondrial to the plastid genome and its subsequent evolution in milkweeds 1273 (Apocynaceae). Genome Biology and Evolution 5:1872-1885. DOI: 10.1093/gbe/evt140.

1274 Straub SCK, Fishbein M, Livshultz T, Foster Z, Parks M, Weitemier K, Cronn R, Liston A. 2011.

1275 Building a model: Developing genomic resources for common milkweed (Asclepias

1276 syriaca) with low coverage genome sequencing. BMC Genomics 12:211. DOI:

$1277 \quad 10.1186 / 1471-2164-12-211$. 
1278 Tai HH, Pelletier C, Beardmore T. 2004. Total RNA isolation from Picea mariana dry seed. Plant

1279 Molecular Biology Reporter 22:93-93. DOI: 10.1007/BF02773357.

1280 Tange O. 2011. GNU Parallel: The command-line power tool. ;login: The USENIX Magazine $1281 \quad 36: 42-47$.

1282 Tennessen JA. 2015. MakeOnemapFormatFromVcfNoParentsTwoGenos.pl.

1283 The French-Italian Public Consortium for Grapevine Genome Characterization. 2007. The 1284 grapevine genome sequence suggests ancestral hexaploidization in major angiosperm 1285 phyla. Nature 449:463-467. DOI: 10.1038/nature06148.

1286 The Tomato Genome Consortium. 2012. The tomato genome sequence provides insights into 1287 fleshy fruit evolution. Nature 485:635-641. DOI: 10.1038/nature11119.

1288 Thorn A, Egerer-Sieber C, Jäger CM, Herl V, Müller-Uri F, Kreis W, Muller YA. 2008. The 1289 crystal structure of progesterone $5 \beta$-reductase from Digitalis lanata defines a novel class 1290 of short chain dehydrogenases/reductases. Journal of Biological Chemistry 283:172601291 17269. DOI: 10.1074/jbc.M706185200.

1292 Van Bel M, Proost S, Van Neste C, Deforce D, Van de Peer Y, Vandepoele K. 2013. TRAPID: an 1293 efficient online tool for the functional and comparative analysis of de novoRNA-Seq 1294 transcriptomes. Genome Biology 14:R134.

1295 Van Bel M, Proost S, Wischnitzki E, Movahedi S, Scheerlinck C, Van de Peer Y, Vandepoele K. 1296 2012. Dissecting Plant Genomes with the PLAZA Comparative Genomics Platform. 1297 Plant Physiology 158:590-600. DOI: 10.1104/pp.111.189514.

1298 Van Zandt PA, Agrawal AA. 2004. Community-wide impacts of herbivore-induced plant 1299 responses in milkweed (Asclepias syriaca). Ecology 85:2616-2629. DOI: 10.1890/03$1300 \quad 0622$.

1301 Vaughan FA. 1979. Effect of gross cardiac glycoside content of seeds of common milkweed, 1302 Asclepias syriaca, on cardiac glycoside uptake by the milkweed bug Oncopeltus fasciatus. 1303 Journal of Chemical Ecology 5:89-100. DOI: 10.1007/BF00987690. 
1304 Wang N, Thomson M, Bodles WJA, Crawford RMM, Hunt HV, Featherstone AW, Pellicer J, 1305 Buggs RJA. 2012. Genome sequence of dwarf birch (Betula nana) and cross-species 1306 RAD markers. Molecular Ecology 22:3098-3111. DOI: 10.1111/mec.12131.

1307 Weitemier K. 2014. fastq_collapse.py.

1308 Weitemier K. 2017. Supplemental data to “A draft genome and transcriptome of common 1309 milkweed (Asclepias syriaca) as resources for evolutionary, ecological, and molecular 1310 studies in milkweeds and Apocynaceae.” DOI: 10.7267/N9M61HDR.

1311 Weitemier K, Straub SCK, Cronn RC, Fishbein M, Schmickl R, McDonnell A, Liston A. 2014. 1312 Hyb-Seq: Combining target enrichment and genome skimming for plant phylogenomics. 1313 Applications in Plant Sciences 2:1400042. DOI: 10.3732/apps.1400042.

1314 Wikström N, Kainulainen K, Razafimandimbison SG, Smedmark JEE, Bremer B. 2015. A

1315 Revised Time Tree of the Asterids: Establishing a Temporal Framework For Evolutionary $1316 \quad$ Studies of the Coffee Family (Rubiaceae). PLOS ONE 10:e0126690. DOI:

$1317 \quad$ 10.1371/journal.pone.0126690.

1318 Willson MF, Rathcke BJ. 1974. Adaptive design of the floral display in Asclepias syriaca L. The 1319 American Midland Naturalist 92:47-57. DOI: 10.2307/2424201.

1320 Woodson RE. 1954. The North American species of Asclepias L. Annals of the Missouri $1321 \quad$ Botanical Garden 41:1-211.

1322 Wyatt R, Broyles SB. 1990. Reproductive biology of milkweeds (Asclepias): Recent advances. In: Kawano S ed. Biological approaches and evolutionary trends in plants. San Diego, 1324 California: Academic Press, Inc., 255-272.

1325 Wyatt R, Broyles SB. 1994. Ecology and evolution of reproduction in milkweeds. Annual Review 1326 of Ecology and Systematics 25:423-441.

1327 Xiao M, Zhang Y, Chen X, Lee E-J, Barber CJS, Chakrabarty R, Desgagné-Penix I, Haslam TM, 1328 Kim Y-B, Liu E, MacNevin G, Masada-Atsumi S, Reed DW, Stout JM, Zerbe P, Zhang Y, 1329 Bohlmann J, Covello PS, De Luca V, Page JE, Ro D-K, Martin VJJ, Facchini PJ, Sensen 1330 CW. 2013. Transcriptome analysis based on next-generation sequencing of non-model 

Biotechnology 166:122-134. DOI: 10.1016/j.jbiotec.2013.04.004.

1333 Yates SA, Chernukhin I, Alvarez-Fernandez R, Bechtold U, Baeshen M, Baeshen N, Mutwakil MZ, Sabir J, Lawson T, Mullineaux PM. 2014. The temporal foliar transcriptome of the perennial C3 desert plant Rhazya stricta in its natural environment. BMC Plant Biology $14: 2$.

1337 Zhan S, Merlin C, Boore JL, Reppert SM. 2011. The Monarch butterfly genome yields insights into long-distance migration. Cell 147:1171-1185. DOI: 10.1016/j.cell.2011.09.052. 
Figure 1

Asclepias syriaca inflorescence.

An inflorescence of $A$. syriaca. Note the floral coronas (white to light pink) surrounding each central gynostegium. Photo credit: Mark Fishbein.

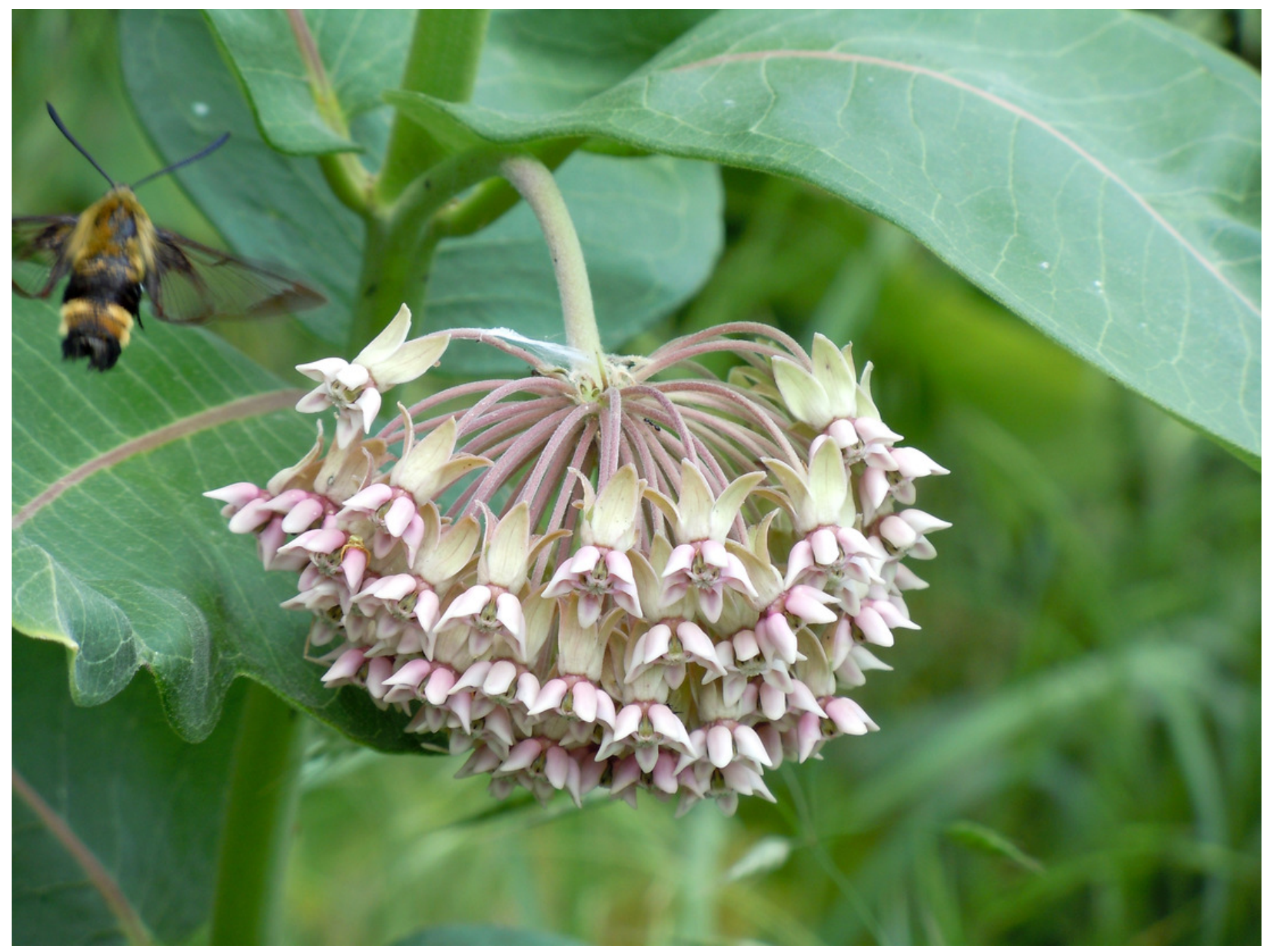


Figure 2

Peptide length histograms of Asclepias, Calotropis, Coffea, and Catharanthus.

Mean and median peptide lengths are provided in the legend.

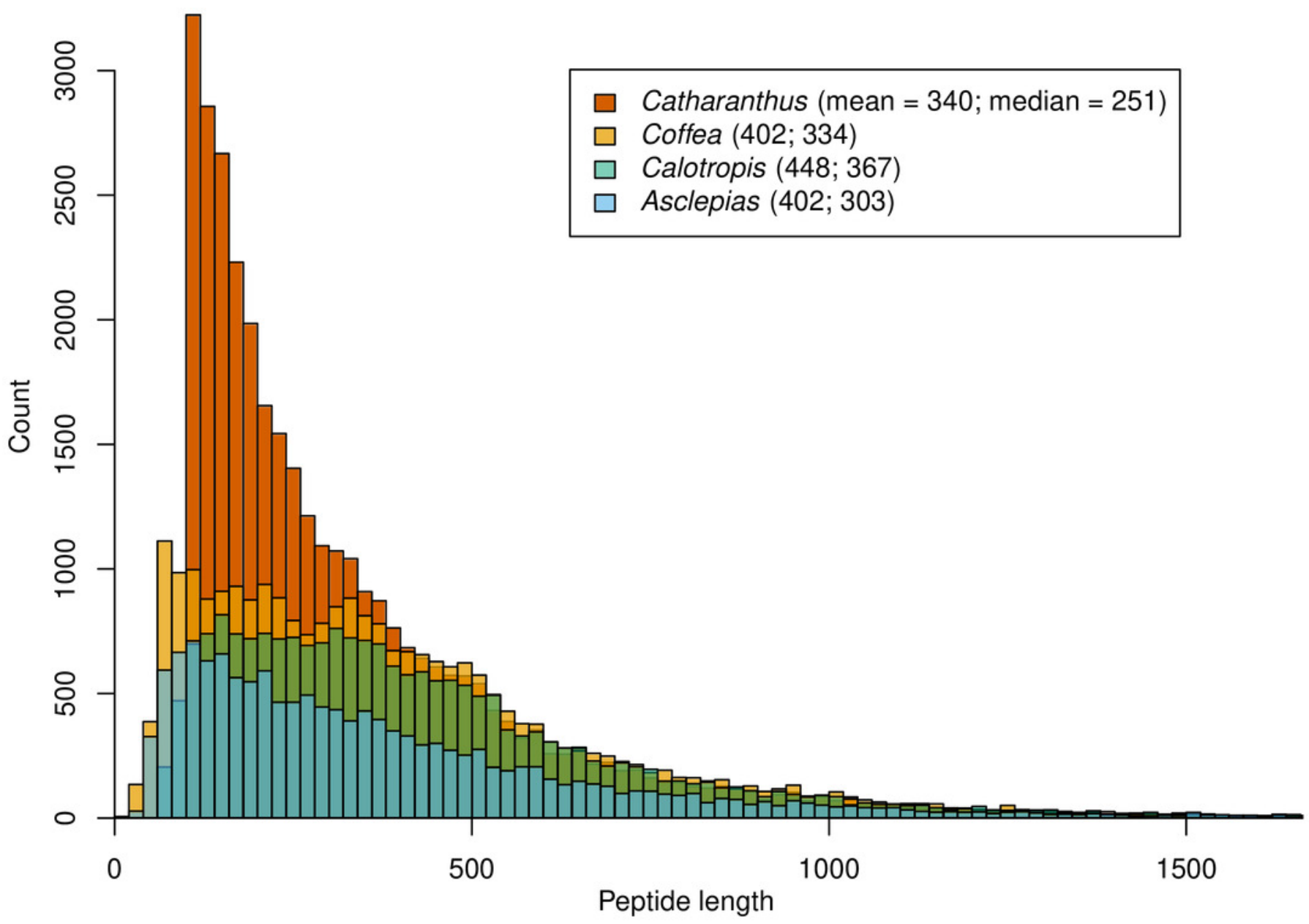




\section{Figure 3}

Gene family evolution in Apocynaceae inferred from transcriptomes.

The ultrametric tree depicts the phylogenetic relationships and estimated divergence times of sampled Apocynaceae and outgroups (Coffea, Vitis). The number of gene birth/death/innovation events per gene per million years across all gene families is shown above the branches. Numbers following tip labels represent the observed number of P5 $\beta R$ gene family paralogs, and the inferred number of paralogs present in common ancestors is shown to the right of nodes. 


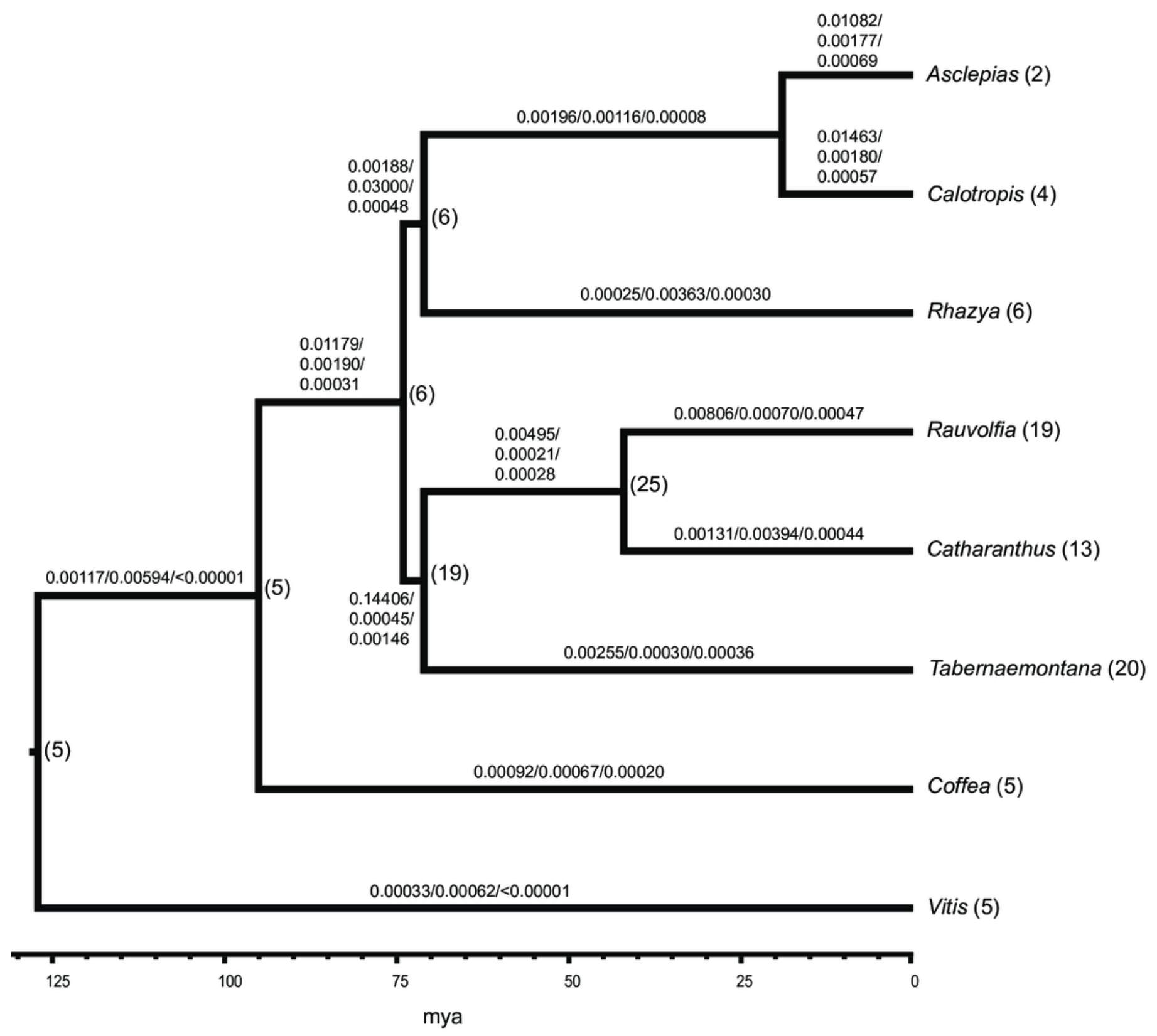


Figure 4

Counts of Asclepias linkage group scaffolds mapping to Coffea pseudochromosomes.

Each column includes scaffolds from a single Asclepias linkage group, each row includes scaffolds mapping to a Coffea canephora pseudochromosome. Coffea chromosome 0 represents unassigned Coffea regions. Dot size is proportional to the number of mapping scaffolds, which is also provided.

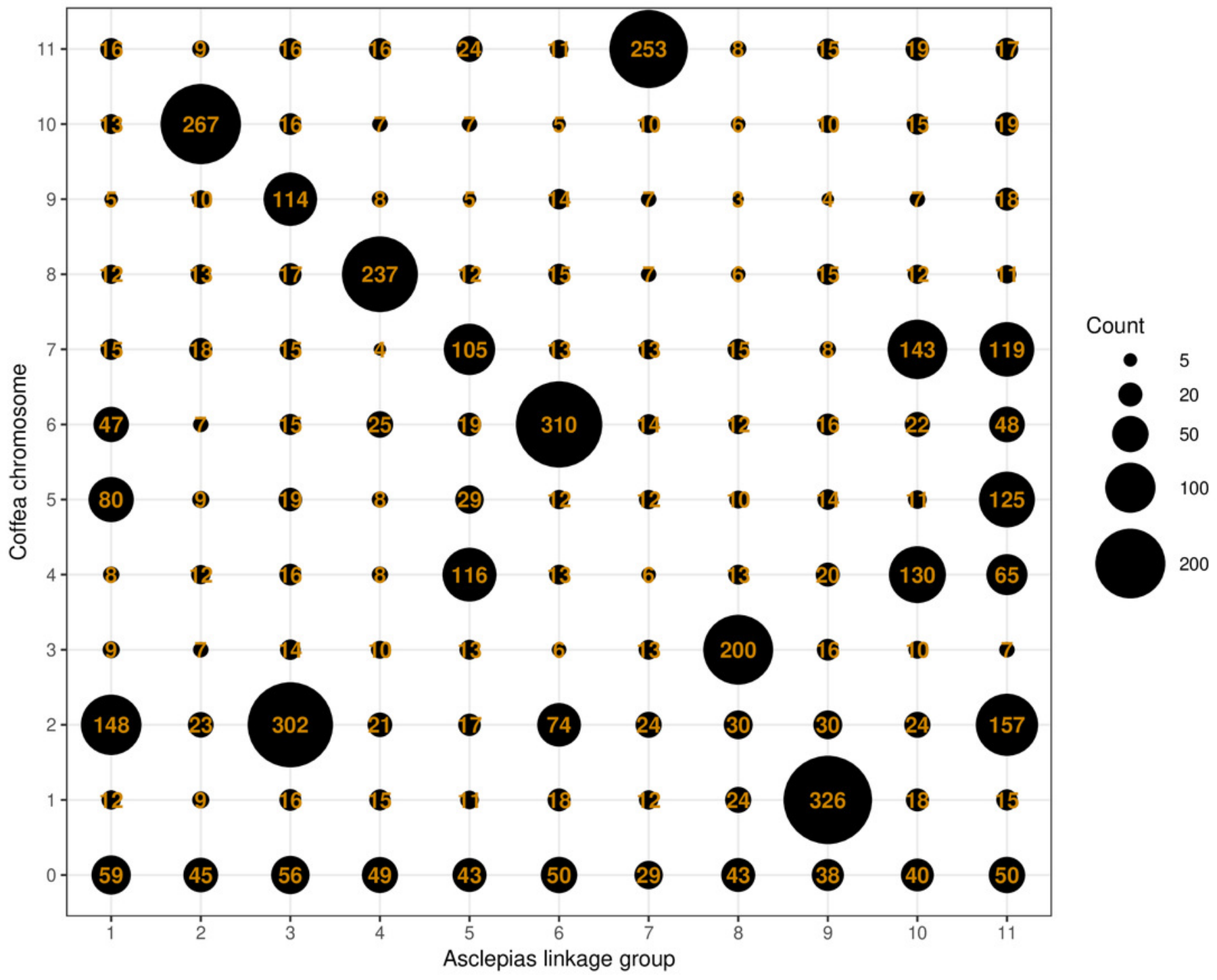




\section{Figure 5}

Asclepias linkage group scaffolds mapped to Coffea pseudochromosomes.

Coffea canephora pseudochromosomes are shown in rows; the $\mathrm{x}$-axis shows distance along each pseudochromosome. Each vertical bar represents one scaffold from the Asclepias core linkage groups, colored by its linkage group membership.

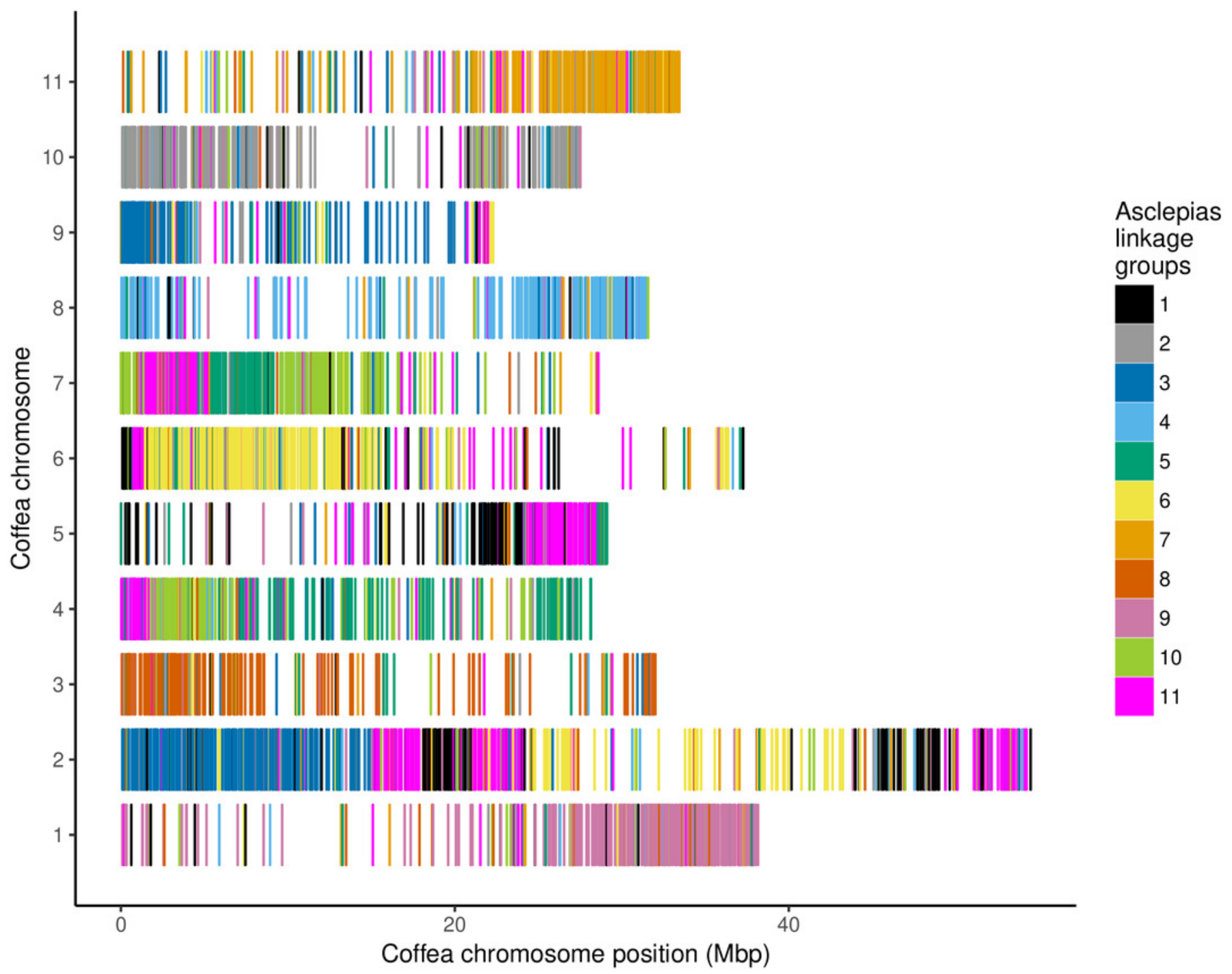




\section{Figure 6}

Maximum likelihood phylogeny of progesterone $5 \beta$-reductase paralogs.

Asclepias syriaca labels indicate the linkage group from which that sequence originates.

Catharanthus and Digitalis labels indicate numbered paralogs isolated from that species.

Rhazya labels indicate the originating supercontig from Sabir et al. (2016) with two paralogs

coming from supercontig 17. Calotropis procera labels indicate the originating transcript from

Kwon et al. (2015). Calotropis gigantea labels indicate the originating contig from Hoopes et

al. (2018). Numbers at nodes indicate aBayes support values. Branch lengths are in substitutions per site. 


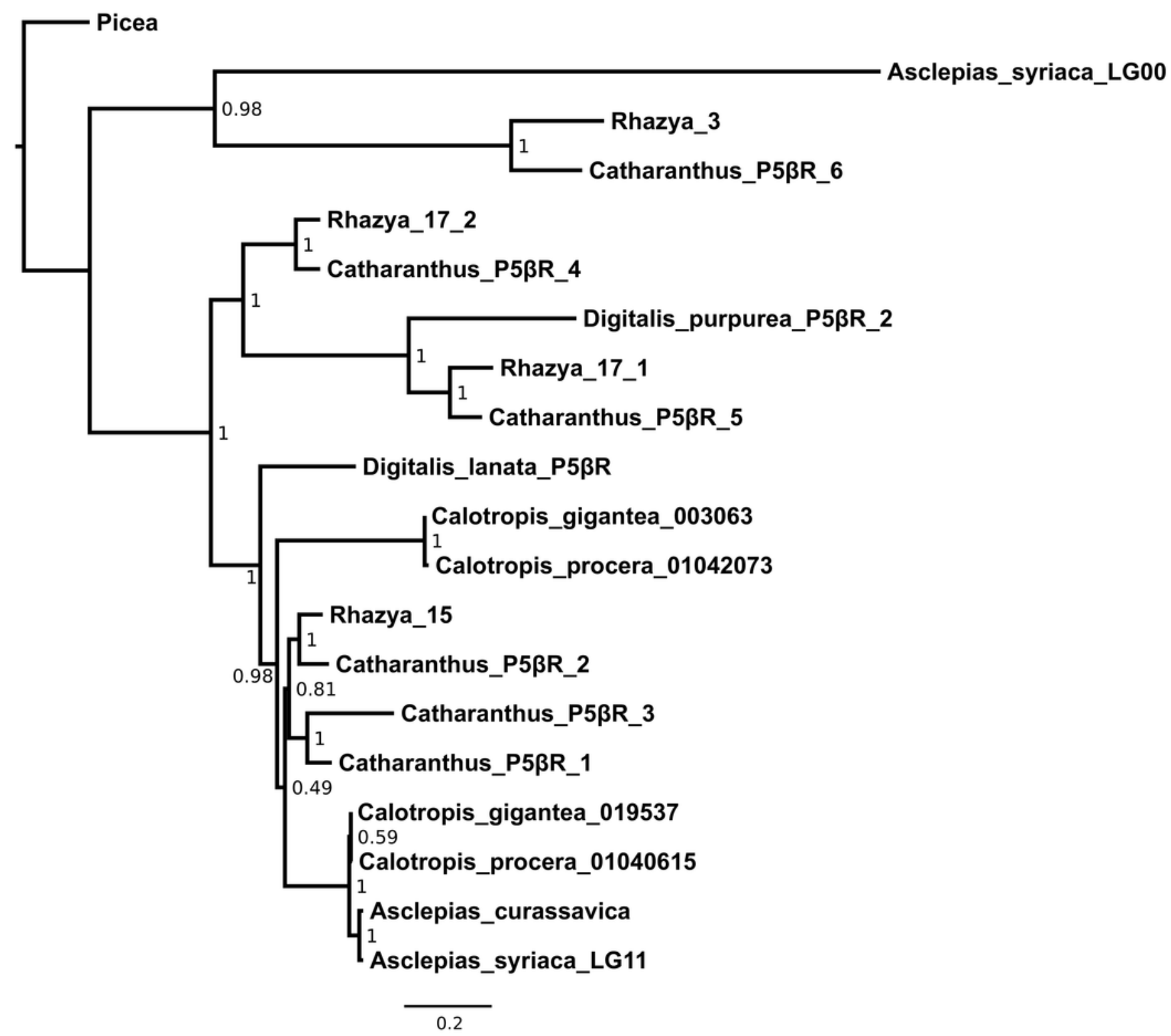




\section{Table 1 (on next page)}

Assembly comparison of Asclepias, Calotropis, Catharanthus, Rhazya, and Coffea.

Sequencing method includes technologies and materials used in sequencing; N50 $=50 \%$ of the assembly is contained in scaffolds of this length or larger, BAC $=$ bacterial artificial chromosome, $\mathrm{SE}=$ single-end, $\mathrm{PE}=$ paired-end. 


\begin{tabular}{|c|c|c|c|c|c|}
\hline Species & $\begin{array}{c}\text { Genome } \\
\text { size (Mbp) }\end{array}$ & $\begin{array}{l}\text { Assembly } \\
\text { size (Mbp) }\end{array}$ & $\begin{array}{l}\text { N50 } \\
\text { (kbp) }\end{array}$ & \# Scaffolds & Sequencing method \\
\hline Coffea canephora & 710 & 568.6 & 1261 & 13,345 & $\begin{array}{l}454 \text { SE \& mate-pair, } \\
\text { Illumina SE \& PE, BACs, } \\
\text { haploid accession }\end{array}$ \\
\hline Rhazya stricta & 200 & 274 & 5500 & 980 & $\begin{array}{l}\text { Illumina PE \& mate-pair, } \\
\text { PacBio, optical mapping }\end{array}$ \\
\hline Catharanthus rosea & 738 & 506 & 27.3 & 41,176 & $\begin{array}{l}\text { Illumina PE, inbred } \\
\text { accession }\end{array}$ \\
\hline Calotropis gigantea & 225 & 157.3 & 805 & 1,536 & Illumina PE \& mate-pair \\
\hline Asclepias syriaca & 420 & 156.6 & 3.4 & 54,266 & Illumina PE \& mate-pair \\
\hline
\end{tabular}


Table 2 (on next page)

Asclepias syriaca sequencing summary.

Machine: Illumina instrument that performed the sequencing; Raw yield, Processed yield: Total Mbp of sequence data before and after read processing. SRA: NCBI Short Read Archive accession number. 


\begin{tabular}{|c|c|c|c|c|c|c|c|c|}
\hline Library type & $\begin{array}{l}\text { Insert size } \\
\text { (bp) }\end{array}$ & Machine & Lanes & $\begin{array}{l}\text { Read length } \\
\text { (bp) }\end{array}$ & Clusters & $\begin{array}{c}\text { Raw yield } \\
\text { (Mbp) }\end{array}$ & $\begin{array}{l}\text { Processed } \\
\text { yield (Mbp) }\end{array}$ & SRA \\
\hline Paired-end & 225 & GA II & 5 & 120 & $193,332,028$ & 46400 & 29171 & SRX2164079 \\
\hline Paired-end & 450 & GA II & 1 & 80 & $22,244,539$ & 3559 & 1530 & SRX322144 \\
\hline Mate-pair & 2000 & MiSeq & $1 / 15$ & 76 & 257,750 & 39 & 34 & SRX2164126 \\
\hline Mate-pair & 2750 & HiSeq 2000 & $1 / 3$ & 101 & $46,704,483$ & 9434 & 2819 & SRX322145 \\
\hline Mate-pair & 3500 & MiSeq & 1 & 33 & $5,815,961$ & 384 & 195 & SRX322148 \\
\hline RNA-Seq Buds & -- & HiSeq 2000 & $1 / 4$ & 101 & $48,085,747$ & 4857 & 2812 & SRX2432900 \\
\hline RNA-Seq Leaf & -- & HiSeq 2000 & $1 / 4$ & 101 & $64,772,831$ & 6542 & 3787 & SRX2435668 \\
\hline & & & \multicolumn{2}{|c|}{$\begin{array}{l}\text { Paired-end total } \\
\text { Mate-pair total } \\
\text { RNA-Seq total }\end{array}$} & $\begin{array}{r}215,576,567 \\
52,778,194 \\
112,858,578\end{array}$ & $\begin{array}{c}49959 \\
9857 \\
11399\end{array}$ & $\begin{array}{c}30701 \\
3048 \\
6599\end{array}$ & \\
\hline
\end{tabular}




\section{Table 3(on next page)}

Asclepias syriaca assembly statistics.

Minimum scaffold: The minimum scaffold size (bp) used for calculations. Sum: The sum of the lengths of all included scaffolds, not including gaps. N80, N50, N20: The length (bp) of the shortest scaffold in the set of largest scaffolds needed to equal or exceed (N/100)(Sum). \# scaffolds: Total scaffolds $\geq$ the minimum size. 


\begin{tabular}{cccccc} 
Minimum scaffold & Sum (Mbp) & N80 & N50 & N20 & \# scaffolds \\
\hline 77 (all) & 265.9 & 317 & 1454 & 7080 & 508851 \\
200 & 229.7 & 621 & 1904 & 8967 & 221940 \\
1000 & 156.6 & 1633 & 3415 & 14019 & 54266 \\
10000 & 42.82 & 12894 & 18998 & 30689 & 2343
\end{tabular}

